\title{
Tri-doped Co-annealed Zinc Oxide Semi-conductor Synthesis and Characterization - Photodegradation of Dyes and Gas sensing Applications
}

\section{Manik Rakhra}

Lovely Professional University

Neha Verma ( $\nabla$ nv0027@gmail.com )

Kanya Maha Vidyalaya https://orcid.org/0000-0003-3761-9205

\section{Research Article}

Keywords: Tri-doped ZnO, Nanoparticles, Gas Sensor, Dyes degradation, DR-31 Dye

Posted Date: March 19th, 2021

DOI: https://doi.org/10.21203/rs.3.rs-307077/v1

License: (c) (i) This work is licensed under a Creative Commons Attribution 4.0 International License.

Read Full License 


\title{
Tri-doped Co-annealed Zinc Oxide Semi-conductor Synthesis and Characterization - Photodegradation of Dyes and Gas sensing Applications
}

\author{
Manik Rakhra ${ }^{1}$, Neha Verma ${ }^{2 *}$ \\ ${ }^{1}$ Assistant Professor, School of Computer science and Engineering, Lovely Professional University, \\ Phagwara, Punjab -144411, India \\ ${ }^{2}$ Assistant Professor, Department of Physics, K.R.M D.A.V College, Nakodar-144040, India
}

nv0027@gmail.com*

\begin{abstract}
Despite the fact that much of the research has been performed on $\mathrm{ZnO}$-based nanoparticles but still a lot of unexplored The synthesis and characterization of the $\mathrm{ZnO}$ Nano rinds, which have been co-created using a simple combustion method, are documented here and are prepared with its sensor and photocatalytic degradations. In, Sn and SB specific quantity was used as dopants, while their effects were co-annealed on glass substrate at different temperatures, i.e. 1.0 percent and 1.5 percent at $500^{\circ} \mathrm{C}, 1100^{\circ}$. At varying temperatures, the samples were coated on to the chosen substrate using doctor blade technique. Crystallite scale was measured to the range of 30-50 nm. At such temperatures the grain size measured for the samples was in range of 50-70 nm. This showed that the prepared Nano rods are well crystalline and have strong optical properties to handle. Studies of X ray diffraction showed the influential point (101). These coated samples designed for nitrogen gas sensing have been tested for the development of smart and functional instruments. Furthermore it was observed that the samples prepared at higher temperatures exhibit better recovery and better reaction time. Valance ion process explains the gas sensors fast reaction and long recovery time. Thus prepared $\mathrm{ZnO}$ nanoparticles are have photocattalytic degredation $(99.86 \%)$ only in 55 min. We observed optimum exposure at an operating temperature of $105^{\circ} \mathrm{C}$. It is notable that morphology of susceptible layer nanoparticles is preserved based on different tri-doping concentrations. The concentration of $\mathrm{T} 2-\mathrm{ZnO}$ nanoparticles for photodegradation of the DR31 dye and $\mathrm{NO}_{2}$ gas sensing applications were 1.0 at.wt $\%$
\end{abstract}

Keywords: Tri-doped ZnO; Nanoparticles; Gas Sensor; Dyes degradation; DR-31 Dye.

\section{Introduction}

In the modern era, it is necessary to save the environment from various occurring problems in the world such as leakage of gas and water pollution. To protect the environment from the hazardous and toxic gases scientists have attracted interest in development of gas sensor. Gas sensor plays a significant role for the detection of poisonous gases. Worldwide researchers are working hard to produce a new variety of sensors. A sensor is an electronic circuit which can sense physical and chemical changes on the surface. For sensing a particular gas, choice of specific material depends on interaction of surface of active sites which are associated with oxygen space and valence ions.

Main cause of water pollution is worldwide growing synthetic organic dyes which are widely used in textile, food and leather industries. To control these problems and save the environment, $\mathrm{ZnO}$ nanoparticles become hotspot for researchers due to their excellent properties such as small size, high sensitivity, high response, recovery time and low cost. Toxic nature of non biodegradable dye considered as serious pollutants which usually create the problem in living organism. Among the various classes of dye, Azo dye having major group of dye which is used in textile industries and low cost. However different types of methods such as sedimation, filtration, adsorption, and photocatalytic degradation are employed because of the soluble nature. In the presence of photocatalyst, photocatalytic degradation is one of the innovative techniques. $\mathrm{ZnO}$ induces redox processes because of the transfer between the valence band and the conduction band as photo-catalyst.

A number of researchers have studied how $\mathrm{Zn}$ should be doping with different dopers such as $\mathrm{In}, \mathrm{Al}, \mathrm{Sn}, \mathrm{Sb}$ and $\mathrm{Ni}$ to improve optoelectronic properties and surface defects[1-5]. Some of the scientists covered the effects of rare terrestrial elements as active dopants on $\mathrm{ZnO}$ interstitial sites, which can help to reduce the electron-hole combination, which is the precondition for gas sensing and photodegradation of colours [6-8]. Research is surrounding around for the fabrication of smart and functional devices, therefore for creation of these devices it is important to control the different structural, optical, morphological, thermal, sensing and 
photocatalytic properties. Liu et.al [9] reported $\mathrm{Ce}, \mathrm{N}$, and $\mathrm{P}$ tri- doped $\mathrm{TiO}_{2} / \mathrm{AC}$ exhibited the highest photocatalytic activity (97.9\%). Han et. al [10] found that $\mathrm{B} / \mathrm{Ag} / \mathrm{F}$ tridoped $\mathrm{SnO} 2-\mathrm{ZnO}$ film is attributed to the low recombination rate of electron-hole pairs. The $\mathrm{C}-\mathrm{N}-\mathrm{S}$ doped $\mathrm{TiO} 2$ was observed for the highest photocatalytic activity for Rhodamine B degradation under visible illumination irradiation[11]. To look at this the concept of tridoped $\mathrm{ZnO}$ has been analysed very rarely under various circumstances. The $\mathrm{ZnO}$ nanostructure is currently very attractive for its useful semiconducting properties, wide bandwidth gap 3,37 eV, large exciton binders $(60 \mathrm{meV})$, non-toxicity, high gain of optics, piezo electricity and low-carbon synthesis $\mathrm{ZnO}$ was successfully employed in chemical and gas sensors, solar cells, light emitting diodes (LEDs), lasers and so forth, because of these excellent properties [12-15]. Different types of morphologies such as nanotubes, nanowires, Nano belts, Nano sheets, Nano flowers, Nano rods has been synthesized by various physical and chemical routes such as sol gel with spin and dip coating [16,17]. Spray pyrolysis, hydrothermal method, Rf magnetron sputtering and simple combustion method [18-21]. Among these techniques, simple combustion method and thermal evaporation technique have more advantageous than others because of their low cost, simplicity in process control, suitable for preparing nanostructure metal oxides.

In the present study, pure and tri-doped $\mathrm{ZnO}$ nanoparticles have been studied which has been prepared by simple combustion method at $400^{\circ} \mathrm{C}$ and then annealed at $500^{\circ} \mathrm{C}$ and again annealed at $1100^{\circ} \mathrm{C}$ (after a gap of 24 hrs). For sensing characterizations pure and doped films were prepared by spin coating technique. Literature also reported that P-type doping is very difficult due to low solubility and compression of acceptor dopants so the same authors have found that co-doping of donor and acceptor is essential for the solubility of acceptor with the stability for ionic charge distribution. Herein, two n-type and one p-type dopant is used. To the best of our knowledge, no published literature has been analyzed the effect of tri dopants on $\mathrm{ZnO}$ nanoparticles with coannealing and compare them with optical, structural, sensing and photocatalytic properties.

\section{Details of the experiment}

\subsection{ZnO nanoparticles synthesis of pure and tridoped}

The syntheses were made using a simple combustion method for the three-doped $\mathrm{ZnO}$ nanoparticles. Triple deionized water was used as solvent in this technique. $0,05 \mathrm{M} \mathrm{Zn}$ nitrate hexahydrates was well mixed in $10 \mathrm{ml}$ of triple deionized water with $0,05 \mathrm{M}$ of sucrose. It was continually mixed with the help of a magnetic agitator at $70^{\circ} \mathrm{C}$ to produce a consistent solution. When mixing, add 0.5 at.wt percent, 1.0 at.wt percent, 1.5 at.wt percent as tri-dopants and mixing, each at.wt percent, each for 30 minutes. The Sigma Aldrich has bought all the chemicals. The Composition Chart is shown in Table 1. After the agitation, the solution was filtered and transferred to an alumina sink that was then placed at $400^{\circ} \mathrm{C}$ in a muffle furnace. After 7-10 min, the material is highly spongy, then crushed and rinsed for 30 minutes under $400^{\circ} \mathrm{C}$. After a gap of 24 hours for 30 min, rinse the result again at $1100^{\circ} \mathrm{C}$. The main objective of the co-annealing is that the nanoparticles are correctly synthesized. The nanoparticles obtained are then thoroughly characterized by structural, optical, morphological, sensing and photocatalytic properties.

\begin{tabular}{|c|c|c|c|c|}
\hline Sample & $\operatorname{In}(\%)$ & $\operatorname{Sn}(\%)$ & $\mathrm{Sb}(\%)$ & Average (\%) \\
\hline Pure- ZnO & & 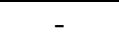 & - & - \\
\hline T1-ZnO & 0.12 & 0.28 & 0.10 & 0.5 \\
\hline $\mathrm{T} 2-\mathrm{ZnO}$ & 0.24 & 0.56 & 0.20 & 1.0 \\
\hline T3-ZnO & 0.37 & 0.70 & 0.43 & 1.5 \\
\hline
\end{tabular}

Table 1 Composition chart for the Pure- $\mathrm{ZnO}, \mathrm{T} 1-\mathrm{ZnO}, \mathrm{T} 2-\mathrm{ZnO}$ and $\mathrm{T} 3-\mathrm{ZnO}$ respectively.

\subsection{Gas sensing application}

The technique for sol gel spin covering is used to produce $\mathrm{ZnO}$ samples for the use of the gas sensor. Sol gel spin cover technique Slowly, on the glass substratum the formulated solution was reduced. The time for spin cover was about 30 seconds, $10 \mathrm{sec}$ at the start was 1,500 rpm and at latter 20 seconds it was about 3,000 $\mathrm{rpm}$. After five coatings, dry the substrate in $1000^{\circ} \mathrm{C}$ in hot air oven for $20 \mathrm{~min}$. These films were produced at $4000 \mathrm{C}$ for one hour before the anneal. A proven static gas sensing was used to study the gas sensing 
characteristics of the prepared nanoparticles (Fig. 1(b)). Fig. 2 The exhaustive examination of the thin films made using the spinning coating technique shown in Fig. 2. The accumulation of gas is obtained by inserting a certain amount of nitrogen oxide into the chamber. The $\mathrm{S}=\mathrm{Ra} / \mathrm{Rg}$ sensor response can be measured. Where Ra resists air, where $\mathrm{Rg}$ resists gas. Results of gas sensing revealed that $\mathrm{ZnO}$ nanoparticles are highly sensitive to nitrogen gas at low operating temperature.

\subsection{Photocatalytic application for photodegradation of DR-31 dye}

In the photoreactor, water circulating jacket was used for maintaining the static temperature to photodegradate DR-31 dye in various conditions [22]. Figure 1 shows a systematic photoreactor diagram (b). The centre was fitted with a 125W UV lamp. $100 \mathrm{ml}$ DR-31 dye solution (30 ppm) in triple deionized water has been prepared The photo degradation percentage has been calculated with the Eq.1

$$
\text { Photodegradation } \%=\frac{C_{0}-\mathrm{C}}{C_{0}} \times 100
$$

Where, $C_{0}$ is initial absorption of dye solution and $\mathrm{C}$ is absorption of degradated dye after regular interval of time.

The spectral composition of $125 \mathrm{~W}$ UV lamp is $255 \mathrm{~nm}$. In the range $320-400 \mathrm{~nm}$ the sample irradiance was 9.2 $\mathrm{mW} / \mathrm{cm}^{2}$. A spectrilight spectro radio meter was used to measure the light intensity.
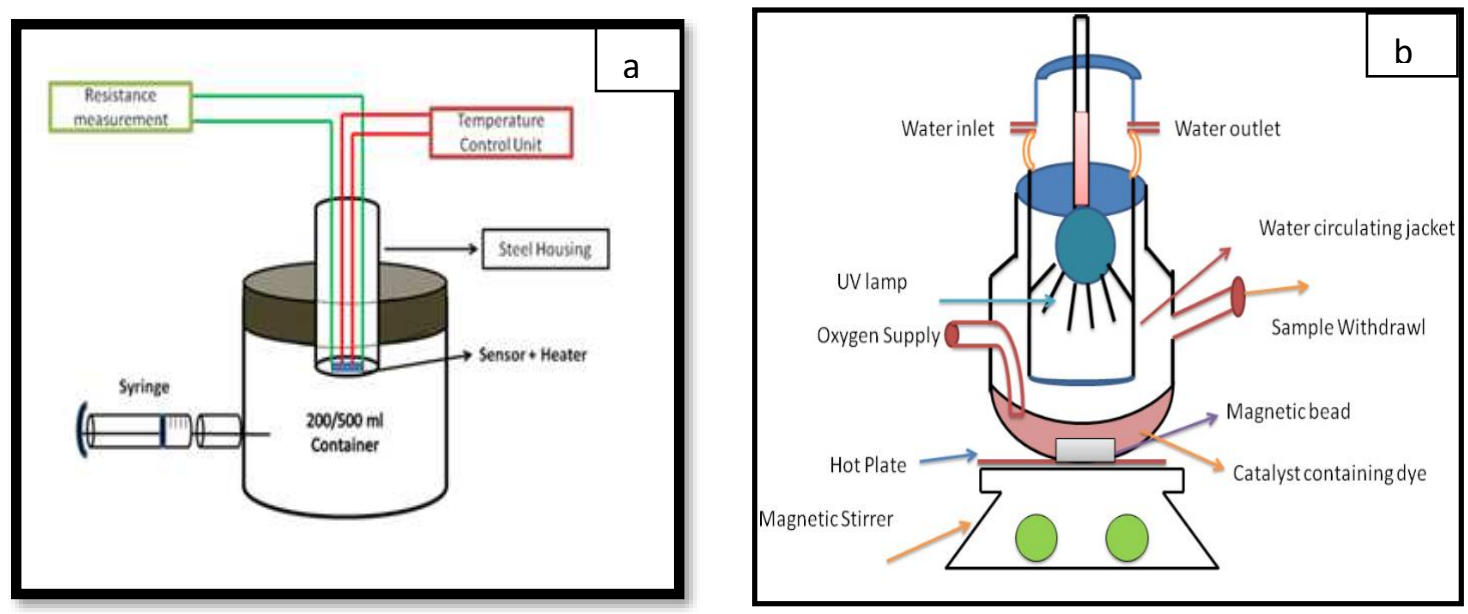

Fig 1 (a,b) Static gas sensing set up, systematic scheme for photoreactor.

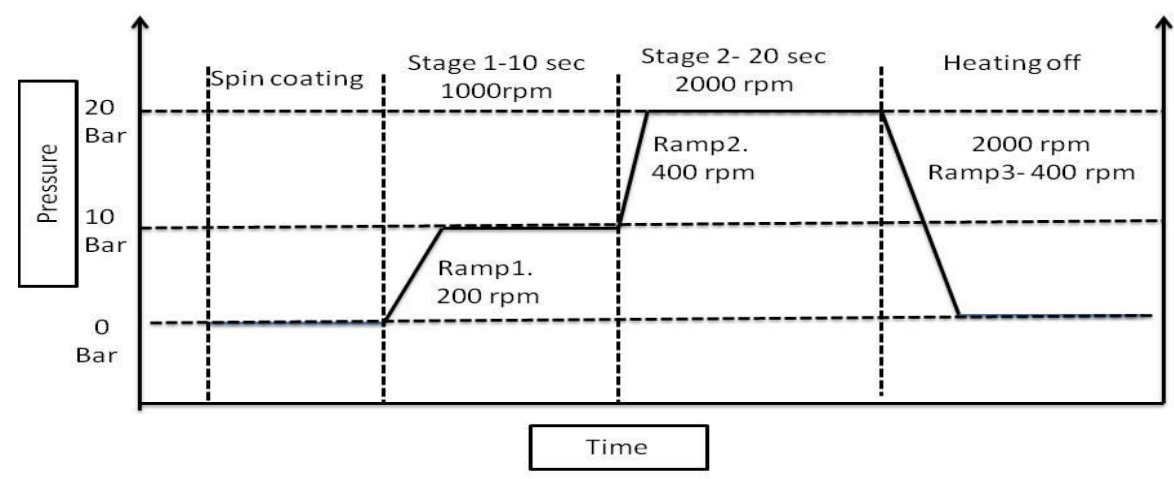


Fig. 2 Programming used for the spin coating technique.

\section{0'Results and discussions}

3.1Pure and tri-doped ZnO structure, morphology, composition, and optical Properties

To look at crystal phases, X-ray diffraction (XRD) patterns of the prepared tri-doped $\mathrm{ZnO}$ nanoparticles were characterised in figure 3 . It shows that XRD's pattern showed reflection at 2 lines $=31,71^{\circ}, 34,40^{\circ}, 36,2^{\circ}, 47,50^{\circ}$, $56,58^{\circ}, 62,85^{\circ}, 67,96^{\circ}, 69,10^{\circ}, 76,02^{\circ}$, corresponding lattice planes (202). The diffraction reflections were well matched to the standard card with the root structure of no JCPDS card No 36-1451. The fact that prominent summits exhibited polycrystalline nature. Peaks due to the large dispersions of doping elements (such as Sn) or the small amount of doping of In and Sb $[9,23]$ were not possibly observed in the other impurities.
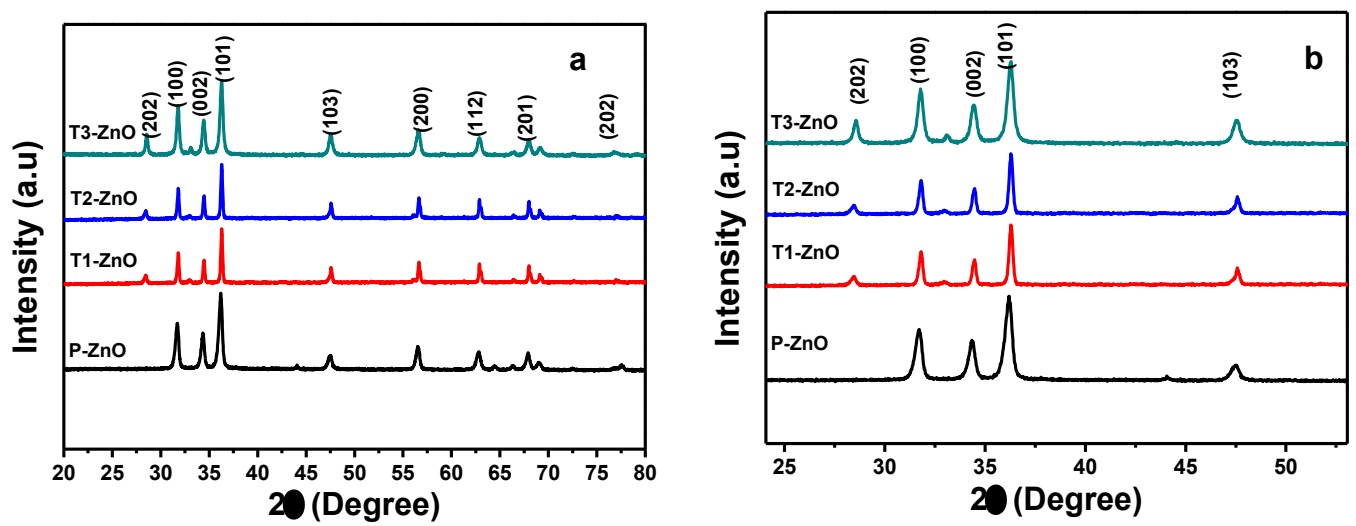

Fig. 3 (a) Low and (b) magnified XRD spectra of Pure, T1-ZnO, T2-ZnO and T3-ZnO respectively.

The lattice spacing was calculated from Bragg's formula

$$
2 \mathrm{~d} \sin \theta=\mathrm{n} \lambda
$$

When $\mathrm{d}$ is the distance between the grid and oscillation, $\beta$ is the width of the wavelength and $\mathrm{n}$ is the order of diffraction.

Crystal size (D) from the Scherrer formula can be found

$$
\mathrm{D}=\frac{K \lambda}{\beta \cos \theta}
$$

Where $\mathrm{D}$ is crystalline, $\mathrm{K}$ is constant, i.e., $0,92, \alpha=0,154 \mathrm{~nm}$, mean $\mathrm{CuK} \alpha 1$ wavelength, $\beta$ is full half maximum width and os is the radius angle of Bragg. Table 2 shows the calculated value of $\mathrm{D}$. This table shows clearly the change in crystal size caused by the dopant's inhibition of crystal growth.

Table 2 represents the comparison of structural properties of pure $\mathrm{ZnO}$ with tri-doped $\mathrm{ZnO}$. It depicts that with the increase in doping percentage the modifications in lattice parameters has been observed [24] which is further responsible for optoelectronic applications.

\begin{tabular}{llcllc}
\hline Sample & Lattice Parameter $\left(\mathbf{A}^{\mathbf{0}}\right)$ & Volume $\left(\mathbf{A}^{\mathbf{0}}\right)^{\mathbf{3}}$ & $\mathbf{d}\left(\mathbf{g} / \mathbf{c m}^{\mathbf{3}}\right)$ & Crystalsize $(\mathbf{n m})$ & Band Gap $(\mathbf{e V})$ \\
\hline $\mathrm{P}-\mathrm{ZnO}$ & $\mathrm{a}=\mathrm{b}=3.257, \mathrm{c}=5.208$ & 47.689 & 11.336 & 32.59 & 3.31 \\
$\mathrm{~T} 1-\mathrm{ZnO}$ & $\mathrm{a}=\mathrm{b}=3.261, \mathrm{c}=5.211$ & 47.843 & 11.300 & 34.65 & 3.36
\end{tabular}




\begin{tabular}{llllll} 
T2-ZnO & $\mathbf{a}=\mathbf{b}=\mathbf{3 . 2 6 7}, \mathbf{c}=\mathbf{5 . 2 1 5}$ & $\mathbf{4 7 . 8 2 9}$ & $\mathbf{1 1 . 3 0 3}$ & $\mathbf{3 6 . 6 3}$ & $\mathbf{3 . 2 9}$ \\
$\mathrm{T} 3-\mathrm{ZnO}$ & $\mathrm{a}=\mathrm{b}=3.253, \mathrm{c}=5.212$ & 47.715 & 11.330 & 39.14 & 3.33 \\
\hline
\end{tabular}

Table-2 Calculated structural properties of pure and tri-doped $\mathrm{ZnO}$ pattern ( $\mathrm{P}-\mathrm{ZnO}, \mathrm{T} 1-\mathrm{ZnO}, \mathrm{T} 2-\mathrm{ZnO}, \mathrm{T} 3-\mathrm{ZnO})$ respectively.

A field emission scan electron microscope investigated General morphology of tri-doped-coannealed $\mathrm{ZnO}$ nanoparticles (FESEM, Jeol-JSM 6100). Fig. 4 represents the composition by different doping percentages of pure and tri-doped $\mathrm{ZnO}$ nanoparticles. The surface was considered fairly rough with uniform grain dimensions of pure $\mathrm{ZnO}$ and $\mathrm{T} 1-\mathrm{ZnO}$ specimens. However, with the increased level of three doping, roughness of the surface was observed to decrease. Fig. 4 especially points to a large number of rod shaped morphologies in $\mathrm{T} 2-\mathrm{ZnO}$ and $\mathrm{T} 3-\mathrm{ZnO}$. Sphere, sticks, drops and other morphologies can be clearly shown. FESEM photographs show that the prepared $\mathrm{ZnO}$ nanoparticles with their various forms and morphologies have a great impact on the different morphologies and time rates of photocatalytic activity and gas sensing effects[25] because of the large volume ratio of $\mathrm{ZnO}$ nanoparticles with a large surface area. $\mathrm{ZnO}$ rod SEM images consist of hexagonal trunks and nanoflowers in some regions combine a bunch of nanorods into one another. It has also found that by increasing the doping percentage the shape of nano-partments is improved. $\mathrm{ZnO}$ nanoparticles have an average diameter and duration of $22,7 \mathrm{~nm}$ and $27,1 \mathrm{~nm}$. The aggregates are nanoparticles scale $40-45$ $\mathrm{nm}$. For synthesising rod-shaped ZNO nanostructures and a large volume-to-surface relationship, existing hexagonal trunks are effective. The calculated XRD crystal size is distinct from SEM for comparison. The difference may be that the SEM size is not crystal-size, but rather the surface morphology. These results show that we become more homogenous with the increase in doping levels. It provides an advantageous high volumeto-surface ratio for application of gas sensing and photo-degradation of the dyes [26].
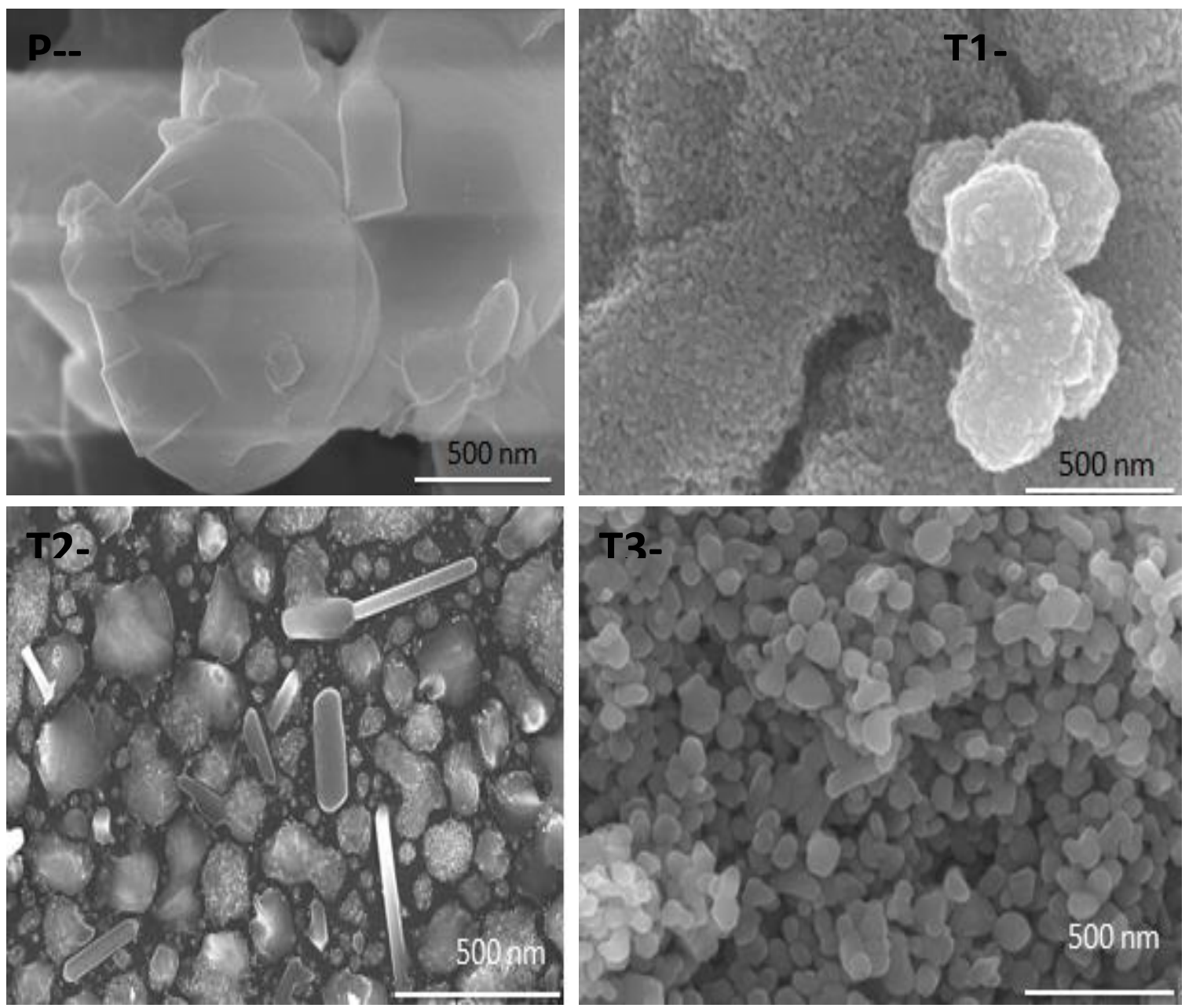
Fig.4.Typical FESEM images ( $\mathrm{P}-\mathrm{ZnO}, \mathrm{T} 1-\mathrm{znO}, \mathrm{T} 2-\mathrm{ZnO}$ and $\mathrm{T} 3-\mathrm{ZnO}$ respectively) for the pure and tridoped $\mathrm{ZnO}$ nanoparticles.

Authors have used the Image $\mathbf{J}$ software and depicts that the size distribution of nanoparticles lies in the range of $35-47 \mathrm{~nm}$.

\section{In case of dispersity:}

$\mathrm{ZnO}$ NPs are effectively precipitate and aggregate depending on several experimental conditions including concentration, ionic strenght, $\mathrm{pH}$. So we have to be careful before using buffers as $\mathrm{ZnO}$ becomes soluble at high and low $\mathrm{pH}$. The range of $\mathrm{pH}$ within which it does not dissolve significantly is rather narrow. The way to prepare the solution should take into account the objective of the measurements. For the stimation of the average size and size distribution of $\mathrm{ZnO}$ nanoparticles (NPs) dispersion at specific $\mathrm{pH}$ and concentration, it could be necessary to do it after sedimentation of the precipitate if any. The impact of the dilution of the dispersion on the size and distribution of size could also be pertinent. If we are making our dispersions from powders, the protocole should be carefully controlled to ensure reproducibility. The value of the zeta potential indicates possible behaviour of the dispersion. In order to view the dispersion there are above mentioned conditions that authors have to consider at the time of synthesis so at this time, it is very difficult to go for zeta potential and dispersity [27].

Surface area of the synthesized sample has been done from the FESEM images by Image $\mathbf{J}$ software. It has found that the surface area lies in the range of $10-15 \mathrm{~m}^{2} / \mathrm{g}$. The average size lies in the range of $50-70 \mathrm{~nm}$.

An UV-Vis spectrophotometer has described the optical properties of pure and tridoped $\mathrm{ZnO}$ nanoparticles. The absorbance spectrums are calculated within $250-750 \mathrm{~nm}$ of these nanoparticles. The maximum absorption rate from 330-380 $\mathrm{nm}$ is shown in Fig. 5. The following relationships allow absorption of spectra to be derived from the transmission spectrum.

$$
\text { Absorbance }=2-\log _{10} \mathrm{~T} \%
$$

Use the Tauc model to calculate the correlation between the uptake rate and photon incident energy of the semiconductor. The following equation is used for direct transition semi-conductor absorption coefficients relating to the length of the optical band.

$$
\alpha h v=A\left(h v-E_{g}\right)^{n}
$$

Where hv is the power,Eg is an optical ribbon gap and $n=1 / 2$ is a Direct Rift, $n=2$ is an Indirect Rift and $\mathrm{ZnO}$ is a direct band gap n-type semicoductor. The pure and tridoped $\mathrm{ZnO}$ nanoparticles optical ribbon gap can be computed using software of origin or manually computed[28]. It has been shown that the range of extrapolation band gaps between 3.29 and $3.33 \mathrm{eV}$ is well equivalent to the energy value obtained from the spectrum of absorption.

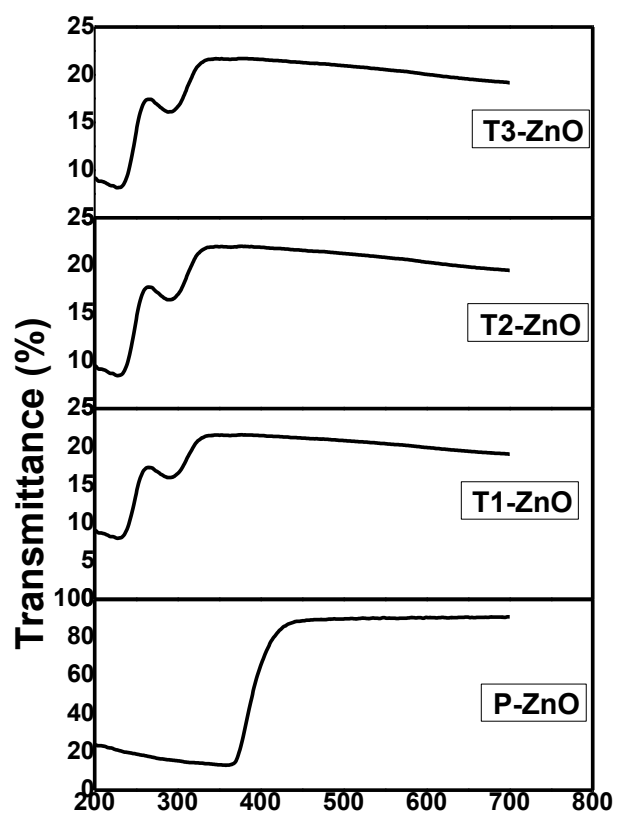


Fig. 5 Typical transmittance spectra of Pure and tri-doped $\mathrm{ZnO}$ nanoparticles (P-ZnO, T1-ZnO, T2-ZnO and $\mathrm{T} 3-\mathrm{ZnO})$ respectively.

The tri-doped $\mathrm{ZnO}$ bandgap along with the affinity to the electron differs according to the doping content variation. Bandgap and electron affinity values are varied due to changes in the ratios $\mathrm{In}, \mathrm{Sn}$, and Sb. The variation in band gap of tri-doped $\mathrm{ZnO}$ is successively decreases with increase in electron affinity. For the better fitting of the curve it is shown that the significance of the affinity of the electron falls within the 4-5 eV range [29]. Fig. 6 depicts the variation of band gap with electron affinity. It teaches us about the amount of energy emitted during the process of gaining electrons by a single atom which is further beneficial for the gas sensing and photocatalytic action [30,31].

The tri-doped $\mathrm{ZnO}$ ribbon and the electron affinity differs depending on the variation in the doping content. Due to changes in ratios In, Sn, and Sb, the bandgap and electron affinity values are varied. With the increase of electron affinity the variation in tri-doped $\mathrm{ZnO}$ bandwidth is successively decreased. The importance of the affinity of the electron falls within 4-5 eV range [29] for the better adjustment of the curve. The variation of the electron affinity band gap shows in Fig. 6. It teaches us how much energy is emitted by a single atom, which is beneficial for gas detection and photocatalytics during electron collection process [30, 31].

Photo-conductance was found in the three-doped $\mathrm{ZnO}$ structure with IDT configuration (Information Design Tool). Fig.7 shows the characteristics of the V-I photoconductive system. The linear V-I characteristics, both forward and reverse, signify the formation of fine ohms between electrode and photosensitive thin layer such ohms, meaning that the photodetection features of UV detector are improved [32]. The linear increase in current with voltage is the linear correlation between the external electric field and the charging carrier, according to the simple model of photo collection and generation. In photoconductive mode, the detector operates. For T2-ZnO samples under UV illumination the current obtained for photography is approximately 151 $\mu \mathrm{A}$ with a $5 \mathrm{~V}$ bias voltage that is well matched to the literature. Authors only selected T2-ZnO here because we found that $\mathrm{T} 2-\mathrm{ZnO}$ has good structural and optical features. In the visible area studied in the construction and optical property, the greatest value of photo current obtained for a sample selected can be attributed to its increased crystallinity as well. This confirms that the tri-dopant ions in the $\mathrm{ZnO}$ would act as cationic dopants in the $\mathrm{ZnO}$ grid to easily transport electrons to the leading band. With UV exposure, the electron that is confined to the dopant detection level can be excited in the leading band, which improves photoconductivity.

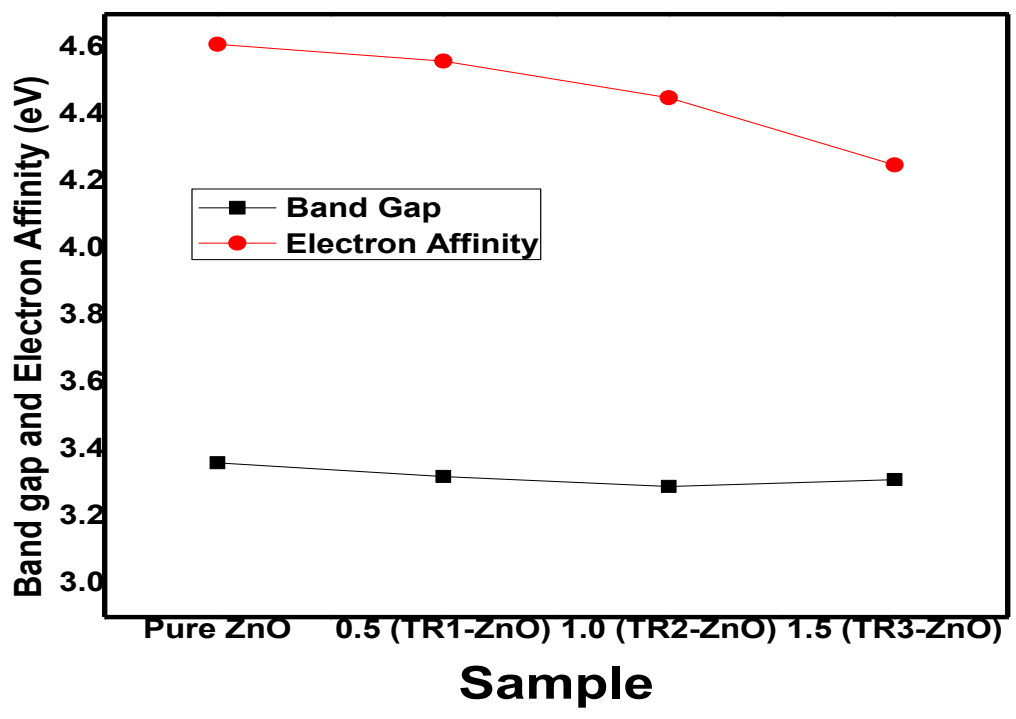


Fig.6 Variation in band gap and electron affinity due to the change in doping content.

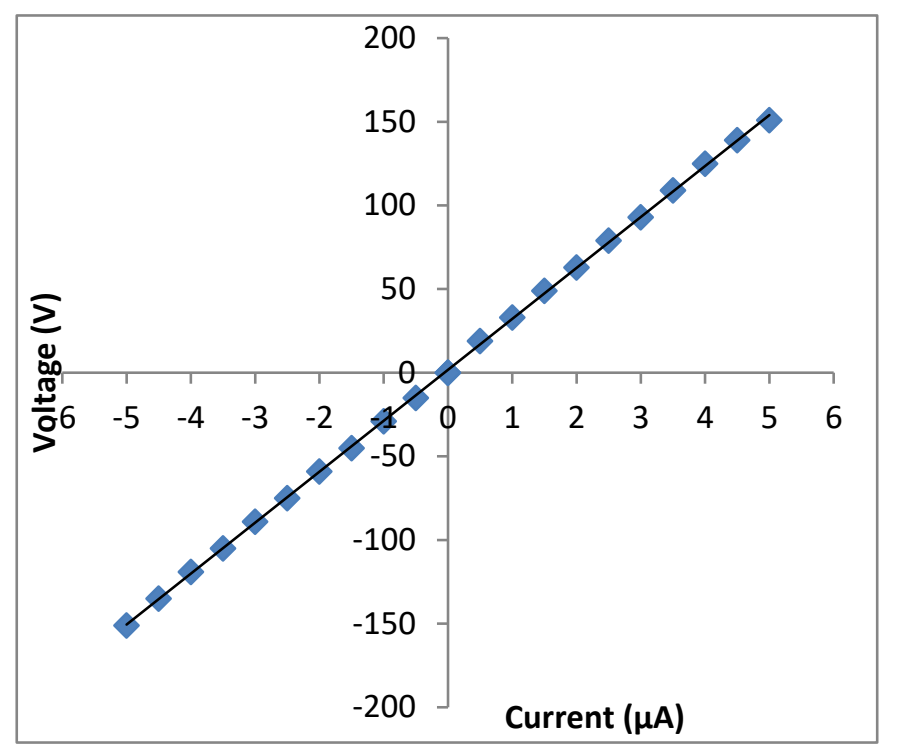

Fig. 7 Linear V-I characteristics under both forward and reverse bias of T2-ZnO respectively.

\subsection{Gas detection system for the tri doped-coannealed $\mathrm{ZnO}$ nanoparticles.}

In the gas sensing activity of the prepared films, different concentrations of the selected gas have been studied for gas sensing. A ratio of change in resistance of the air and gas sample to air resistance is defined as the sensitiveness of the target gas.

$$
\mathrm{S}=\frac{\mathrm{Rg}-\mathrm{Ra}}{\mathrm{Ra}}
$$

where $\mathrm{R}_{\mathrm{g}}$ is resistance in gas and $\mathrm{R}_{\mathrm{a}}$ is resistance in air

For the gas sensing activity thin film has been used. This film preparation has been done by the Doctor Blade method. Same authors reported that the Doctor Blade technique is better to determine the gas sensing property [28]. It has also found that pellet shaped nanoparticles does not give the better result for gas sensing activity. This may be due to breakage of grain boundaries with the application of pressure which can be ignored in case of films formation. Authors has found that co annealed samples provides better result which may be due to the batter synthesis of this film on the selected substrate. Fig. 8 depicts the sensitivity against 35 ppm of the nitrogen gas. This sensitivity is the temperature-dependent sensitivity. From this figure it has found that $105^{\circ} \mathrm{C}$ is the optimized temperature for the pure and tri-doped samples.In the case of the smaller molecules of the sensing materials surface, or oxygen adsortion, above this temperature, all of the samples decreased sensitivity.

The time response curve for all samples is shown in Fig. 9. This figure also tells us the answer and recovery time information. The response time is the time that the sensor takes to increase its highest resistance to target gas exposure. Restoration time is the time it takes to get the initial resistance back. Fig. 9 is a rapid reaction and fast recovery of the tri-doped nanoparticles. This rapid reaction can be due to the acceleration of gas oxidation. This was also predicted by the increased surfacto-volume relationship, defect density and increased ribbon gap, that the reaction and recovery time in tri-doped $\mathrm{ZnO}$ samples may be improved. This helps to further reduce the combination of electron-holes. 


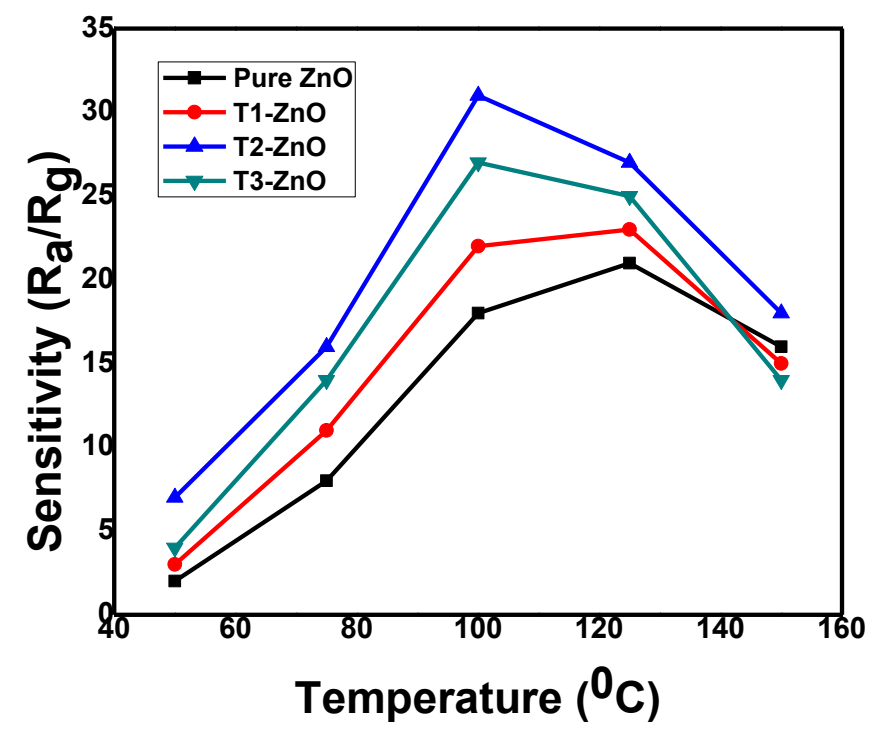

Fig. 8 Sensitivity of Pure and tri-doped $\mathrm{ZnO}$ based sensor towards $\mathrm{NO}_{2}$ gas sensor.

The proposed mechanism of the tri- $\mathrm{ZnO}$ - samples was tested, and it was found that when $\mathrm{Zn}$ and $\mathrm{O}$ combine, $\mathrm{Zn}$ loses the valence electrons to oxygen and then the size of the atom shrinks as the oxygen atom increases in size due to loss of electrons. This variability in size may be due to the disparity in $\mathrm{Zn}$ and oxygen atomic radius.

Tri-doped $\mathrm{ZnO}$ films undergo chemical absorptive changes in the presence of an atmospheric oxygen by trapping electrons in the conduction band known as recombination as oxygen molecules are adsorbed on its surface. By raising the resistance value, this will decrease the barrier height for electron to transport there. This helps increase gas sensor performance. Temperature plays an important role in controlling this mechanism.

The metal oxide gas sensing system is often difficult. This is based on chemical resistance theory. This included functions transducers and receptors. Transducer helps to convert the chemical signal into an electrical signal and receptor is supplied by contact with metal oxide either as a donor or as a carrier acceptor [34]. The increase in sensitivity is due to the increase in the surface reaction rate.

$$
\mathrm{NO}_{2} \text { (gas) }+\mathrm{e}^{-} \longrightarrow \mathrm{NO}_{2}^{-}{ }_{(\mathrm{ads})}
$$

The absorption kinematics are explained as below

$$
\begin{aligned}
& \mathrm{O}_{2} \text { (gas) } \longleftrightarrow \mathrm{O}_{2} \text { (adosrbed) } \\
& \mathrm{O}_{2} \text { (adosrbed) }+\mathrm{e}^{-} \longrightarrow \mathrm{O}_{2}^{-} \\
& \mathrm{O}_{2}^{-}+\mathrm{e}^{-} \longleftrightarrow 2 \mathrm{O}^{-}
\end{aligned}
$$

When sensor is exposed to oxidizing $\mathrm{NO}_{2}$ gas, it reacts with oxygen ions leading to the formation of adsorbed $\mathrm{NO}_{2}$ gas as given below

$$
\begin{aligned}
& \mathrm{NO}_{2}(\text { gas })+\mathrm{e}^{-} \longrightarrow \mathrm{NO}_{2}(\text { ads }) \\
& \mathrm{NO}_{2}(\text { gas })+\mathrm{O}_{2}^{-}+2 \mathrm{e}^{-} \longrightarrow \mathrm{NO}_{2}^{-}(\text {ads })+2 \mathrm{O}_{2}(\text { ads })
\end{aligned}
$$


Fig. 10 shows the adsorption process of the $\mathrm{NO}_{2}$ molecule on the surface is illustrated; $\mathrm{O}_{2}$ adsorption simultaneously is not seen here. At Fig. 11 the possible reaction between $\mathrm{NO}_{2}$ and $\mathrm{O}_{2}{ }^{-}$adsorbed is presented in a schematic manner.
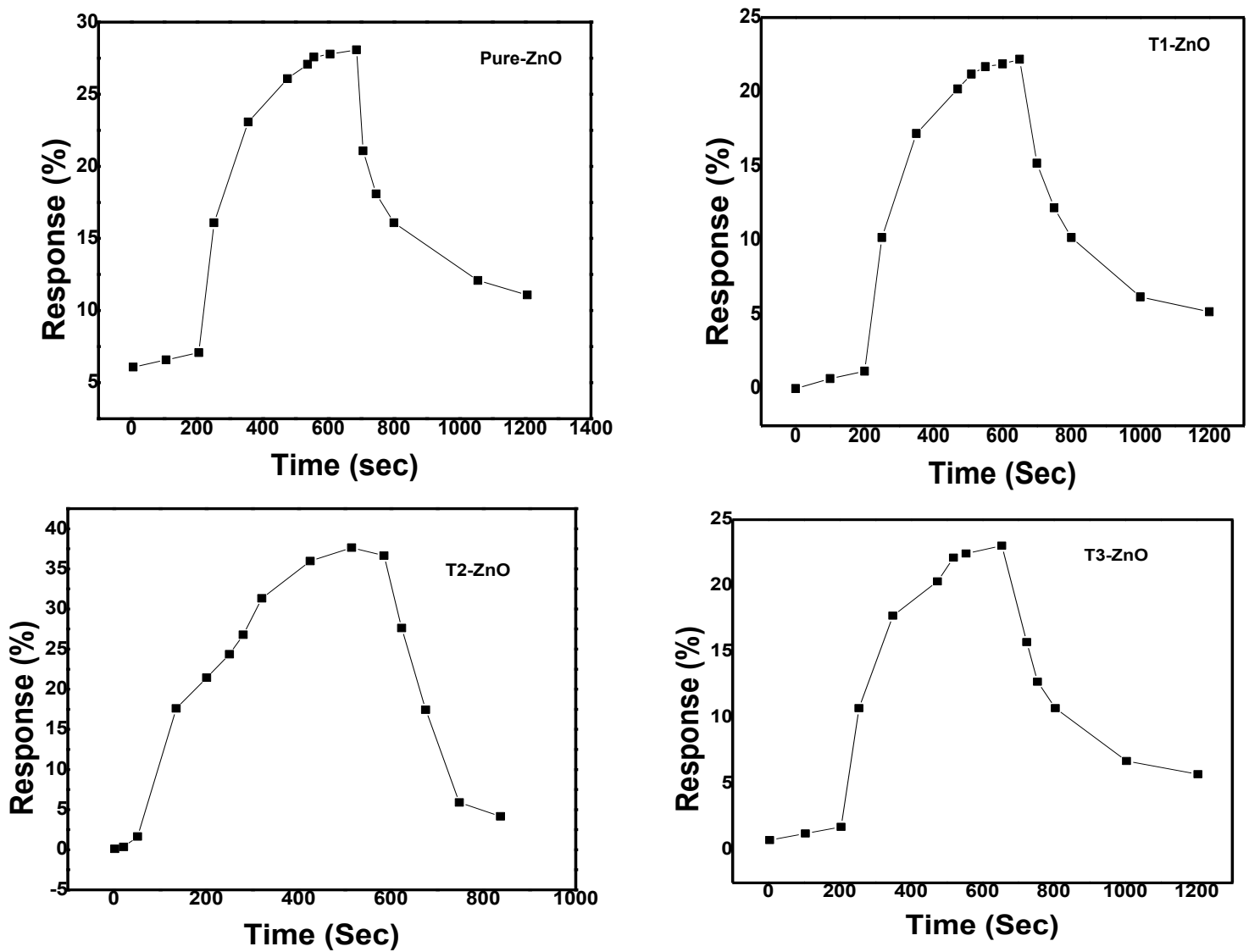

Fig. 9 Gas sensing response for pure $\mathrm{ZnO}, \mathrm{T} 1-\mathrm{ZnO}, \mathrm{T} 2-\mathrm{ZnO}$ and $\mathrm{T} 3-\mathrm{ZnO}$ thin films.

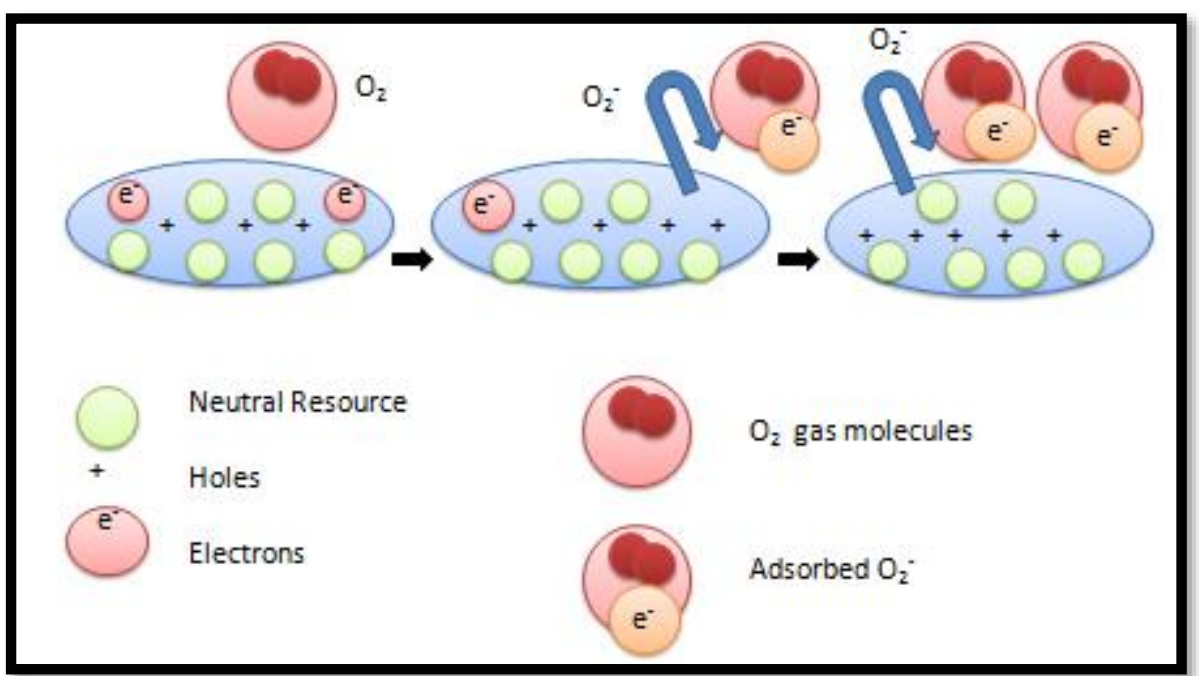


Fig. 10 Schematic illustration of adsorption of $\mathrm{O}_{2}$ gas molecules.

4.2.

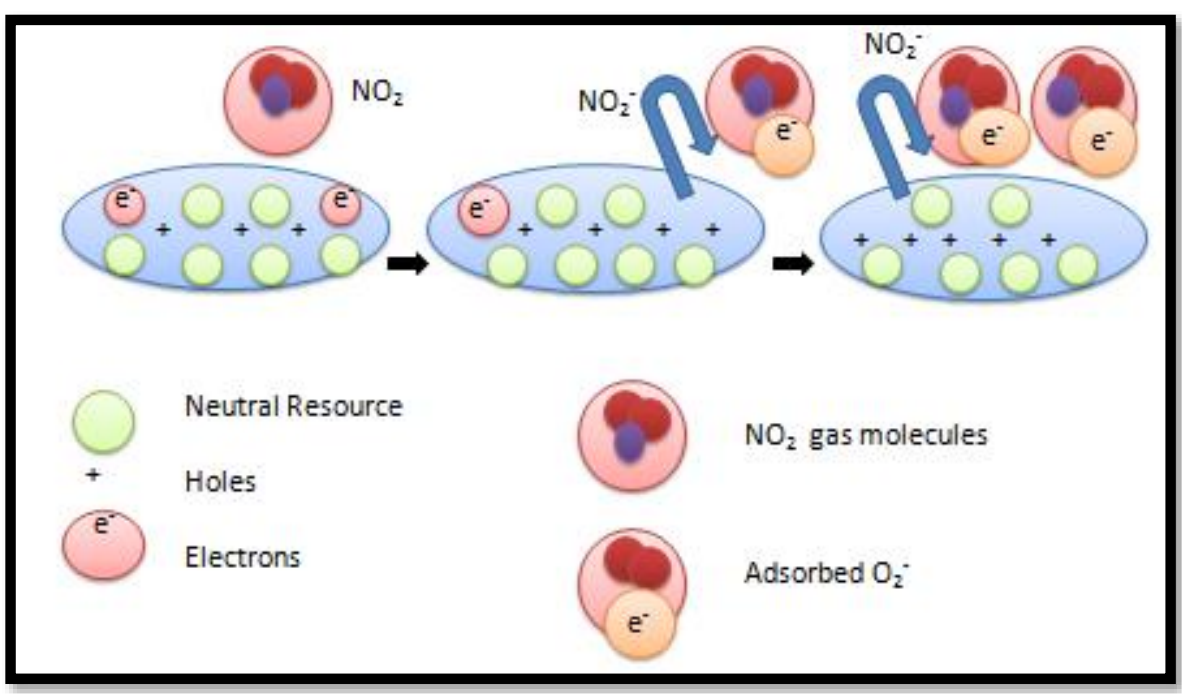

Photocatalytic Property of DR-31 using synthesized Pure ZnO, T1-ZnO, T2-ZnO and T3-ZnO nanoparticles

UV-Vis spectroscopy was investigated for photocatalytic degradation. The pure and three-doped $\mathrm{ZnO}$ nanospectrum spectrum from 200-750 nm is shown in Fig. 12. Fig. 12. A further decrease in absorbance intensity is evidence for effective photocatalytical activity under UV radiation in the pre-produced nanoparticles. Fig.13 shows that the degradation of percentages with an increase in doping concentration is significantly increasing. The results indicate the full photogravation of the DR-31 dye under UV irradiation only within 55 min in the sample of $\mathrm{T} 2-\mathrm{ZnO}$ (1.0 at. wt percent). The proportion of $\mathrm{ZnO}$-pure and $\mathrm{ZnO}$-triped degradation levels has increased from $80 \%$ to $99,86 \%$, indicating that $\mathrm{T} 2-\mathrm{ZnO}$ is the finest photocatalyst for dye degradation. The proposed DR-31 dye picture degradation mechanism[34] is illustrated in Fig. 14.

Photocatalytic water cleavage generates oxygen, as the perfect fuel that only produces water. Researchers worldwide are doing everything they can to develop a highly efficient UV irradiation water splitting system. Efficiency is very important when converting light energy into chemical energy. The efficiency calculation methods are of two types: a method based on energy and a method for quantum efficiency. The most important point of a photocatalysis is the possibility of the electron and hole at the position of the conduction ribbon at the top, even if the light of semi-conductive material is used as a photocatalyst. When a photocatalyst completely absorbs the light of $1,23 \mathrm{eV}$ energy, and all the generated conversion efficiencies are $100 \%$, the efficiency of conversion is halved when a wavelength of $504 \mathrm{~nm}$ is used. The maximum absorption of DR-31 (Photocatalytic Reaction) is $504 \mathrm{~nm}$ in the recent research Fig. 12. In the recent investigation. From the literature surveyed, I found that $50 \%$ is the photocatalytic reaction conversion efficiency.
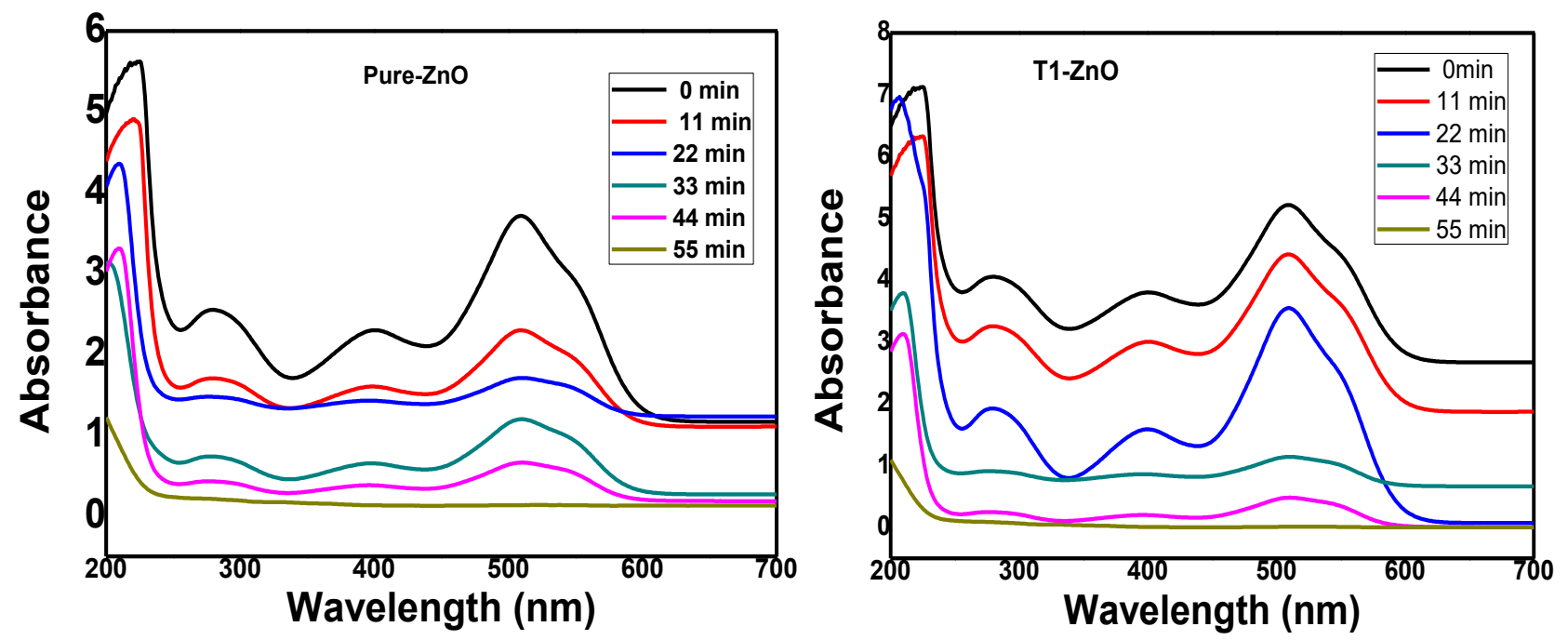

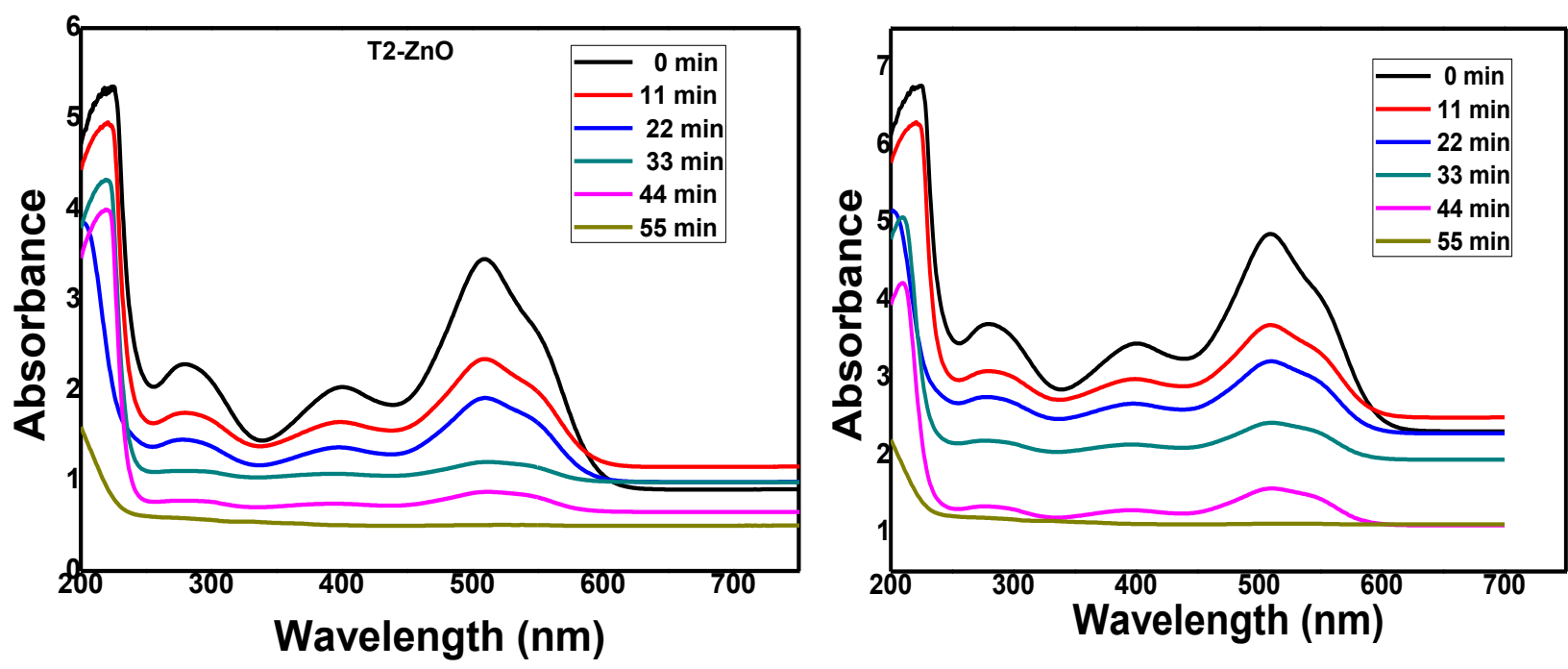

Fig. 12 UV-Vis spectra plot for photodegradation of DR-31 dye for Pure- ZnO, T1-ZnO, T2-ZnO and T3-ZnO respectively.

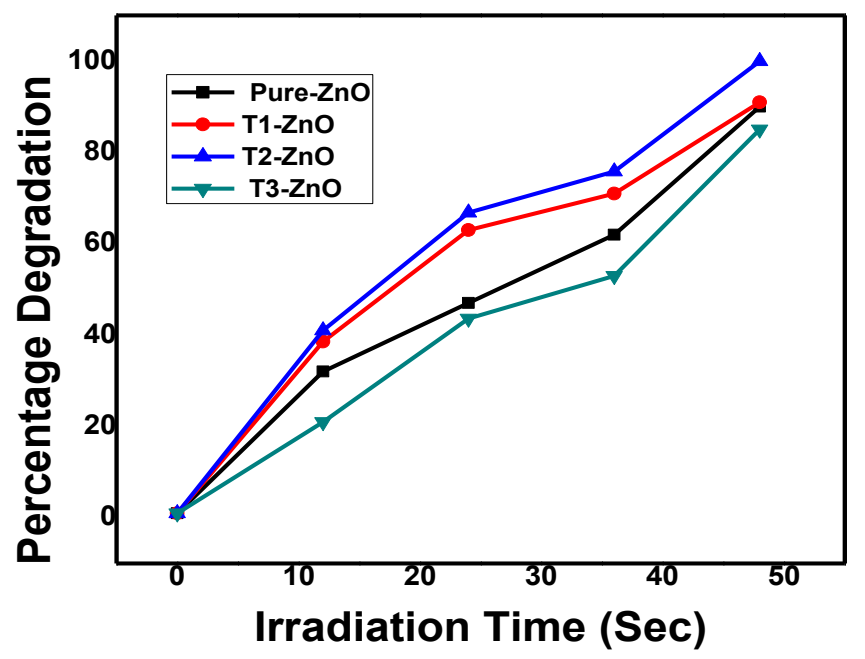

Fig. 13 Percentage degradation of DR-31 dye for Pure-ZnO, T1-ZnO, T2-ZnO and T3-ZnO respectively.

DR-31 dye was suggested as physisorbed and chemisorbed to the surface of three-doped ZnO nanoparticles, which induces a series of photo-induced redox reactions through the formation of electronhole pairs (excitons). The optimised band gap for tridoped $\mathrm{ZnO}$ nanoparticles prevents recombinants from being formed. Then conductive strip electrons are created by reducing the chemisorboed $\mathrm{O} 2$ on the surface of the tri-doped nanoparticles $\mathrm{ZnO}$ (eqs. (13)-(17)), to create various free oxygenated radicals such as $\mathrm{O} 2-\mathrm{OH}$. In addition, ionisation and oxidation of water molecules often include positively charged holes in the valance band. OH-free radical agents (eq. (17)). The radicals produced in the .OH form a non-selective oxidant which oxidises aromatic colours by removing their aromatic rings and transforming them into non-toxic chemicals.

$$
\begin{gathered}
\mathrm{O}_{2}+\mathrm{e}^{-} \mathrm{CB} \longrightarrow \mathrm{O}_{2} \cdot- \\
\mathrm{O}_{2} \cdot{ }^{-}+\mathrm{H}_{2} \mathrm{O} \longrightarrow \mathrm{HO}_{2} \cdot+\mathrm{HO}^{-} \\
\mathrm{HO}_{2} \cdot+\mathrm{HO}_{2} \longrightarrow \mathrm{H}_{2} \mathrm{O}_{2}+\mathrm{O}_{2}
\end{gathered}
$$




$$
\begin{aligned}
& \mathrm{H}_{2} \mathrm{O}_{2}+\mathrm{O}_{2}^{-} \longrightarrow \mathrm{HO}^{-}+\mathrm{HO}^{-}+\mathrm{O}_{2} \\
& \mathrm{H}_{2} \mathrm{O}+\mathrm{ZnO}\left(\mathrm{h}^{+} \mathrm{vB} \longrightarrow \mathrm{ZnO}+\mathrm{HO}^{\circ}\right.
\end{aligned}
$$

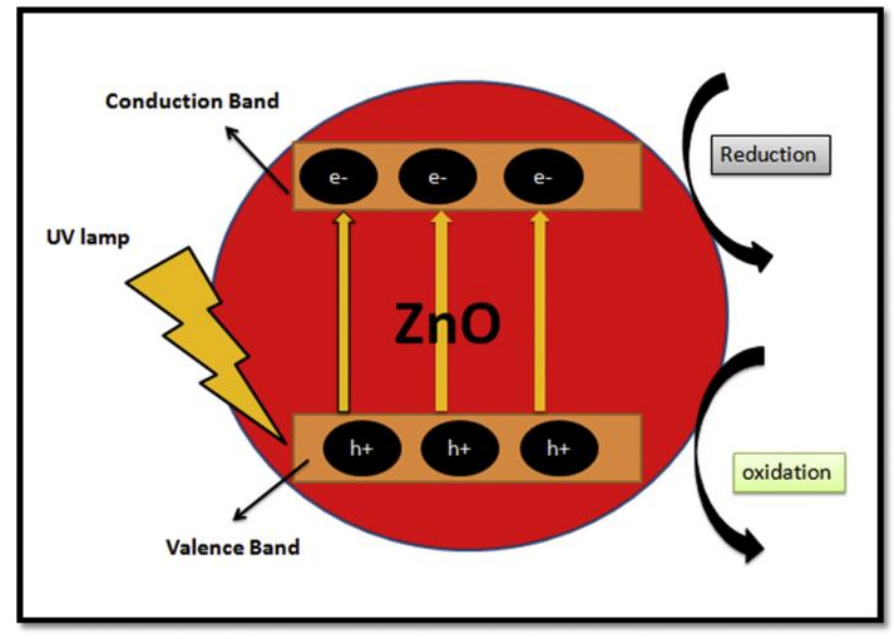

Fig. 14 Mechanism for the dye degradation.

Fig. 11 reflects the possibility of Tri--doped ZNO nanoparticles being photocatalyed. Doping should increase surface defects that contribute to the improvement of photocatalytic function. Literature has stated the wavelength of Photoexciton for light is $388 \mathrm{~nm}$ [35] which can create electron-hole pairs through oxidation and reduction of $\mathrm{O} 2$ radicals reactions. Similarly neutral, single and double-loaded $\mathrm{ZnO}$ oxygen vacancies play a critical role in enhancing the photocatalytic capability of prepared nanoparticles. This causes the rate of photodegradation to increase at higher atomic value, each of which decreases the number of free electrons. 4.3 Proposed Tri-doped $\mathrm{ZnO}$ photocatalytic mechanism.

The surface defect which tends to improve the photocatalytic operation should be increased by a different concentration of doping. The wavelength of light for Photoexciton was $388 \mathrm{~nm}$, which creates a pair of electron panels, oxidation and reducing reactions which dramatically generate $\bullet \mathrm{OH}$ in the presence of $\mathrm{O} 2$. Doping ions can also work as efficient scavenger electrons that reduce the recombination of electron-hole by different doping methods. Furthermore, neutral, single and twice loaded oxygen vacancies $\left(\mathrm{V}_{0}{ }^{+}, \mathrm{V}_{\mathrm{O}}{ }^{++}\right)$for $\mathrm{T}_{2}$, $\mathrm{ZnO}$ can enhance photo-catalytic performance of ready-made nanoparticles. This increases the percentage of photo-degradation when atomic doping is greater than free electrons.

\subsection{Conclusions}

To say well synthesized Pure and tri-doped ZnO nanoparticles have been researched via the quick and affordable process of simple combustion and Doctor Blade technique. Detailed analysis methodology has assisted in the synthesized nanostructures becoming fully crystalline and exhibiting the highest optical properties. At an operating temperature of $105^{\circ} \mathrm{C}$, the rod-shaped morphology (T2-ZnO) displays outstanding gas sensing behaviour against $\mathrm{NO}_{2}$ emissions. Synthesized nanoparticles are also used for photocatalytic action, i.e. DR-31 dye photodegradation. Such research indicated that the rate of photodegradation has decreased with the rise in the level of tri-doping. In the other side, this percentage rise was observed for the amount doping interest chosen and then the amount reduction was detected. This latest research indicates that T2$\mathrm{ZnO}$ can be called suitable for both applications.

\section{Acknowledgments}

Authors are grateful to the Principal KRM DAV College Nakodar and Lovely Professional University, Phagwara for providing FESEM and XRD facility. 


\section{Summary}

- Tri- doped ZnO (In,Sn and Sb) were synthesized by Simple combustion method.

- Different concentrations of doping (0.5 at.wt\%, 1.0 at.wt \%, 1.5 at.wt\%) were used as dopants.

- $1.0 \%$ of tri-doped ZnO exhibited almost complete photodegradation of DR-31 dye.

- Photocatalytic activities for all the samples were observed in $48 \mathrm{~min}$.

- Gas sensing efficiency has been improved in case of T2-ZnO.

\section{Conflict of Interest}

There is no any conflict of interest.

\section{References}

[1] Qi J, Zhang H, Lu S, et al (2015) High performance indium-doped ZnO gas sensor. Journal of Nanomaterials. doi: 10.1155/2015/954747.

[2] Srinatha N, No YS, Kamble VB, et al (2016) Effect of RF power on the structural, optical and gas sensing properties of RF-sputtered Al doped ZnO thin films. RSC Adv 6:9779-9788. doi: 10.1039/C5RA22795J.

[3] Nath RK, Nath SS, Sunar K (2012) Sn-doped Zinc Oxide thin films for LPG sensors. Journal of Analytical Science and Technology 3:85-94. doi: 10.5355/JAST.2012.85.

[4] Hsiou Y, Hung W, Wang C (2015) Fabrication of Sb-doped p-type ZnO Thin Films by Pulsed Laser Deposition. 2:60-64. doi: 10.5147/ajms.2015.0166.

[5] Raja K, Ramesh PS, Geetha D (2014) Synthesis, structural and optical properties of ZnO and $\mathrm{Ni}$-doped ZnO hexagonal nanorods by Co-precipitation method. Spectrochimica Acta - Part A: Molecular and Biomolecular Spectroscopy 120:19-24. doi: 10.1016/j.saa.2013.09.103

[6] Bhatia S, Verma N, Bedi RK (2016) Optical application of Er-doped ZnO nanoparticles for photodegradation of direct red - 31 dye. Optical Materials 62:392-398. doi: 10.1016/j.optmat.2016.10.013

[7] Bhatia S, Verma N (2018) Erbium-doped nanoparticles/films for enhancing percentage photodegradation of direct red-31 dye. Journal of Materials Science: Materials in Electronics 0:1-11. doi: 10.1007/s10854-018-9634-7.

[8] Khataee A, Darvishi R, Soltani C, et al (2014) Synthesis and Characterization of DysprosiumDoped ZnO Nanoparticles for Photocatalysis of a Textile Dye under Visible Light Irradiation.

[9]. Liu D, Liu Y, Wu Z, et al (2016) by microwave radiation with visible light response for naphthalene. Journal of the Taiwan Institute of Chemical Engineers 0:1-8. doi: 10.1016/j.jtice.2016.10.002

[10] Activities P, Han K, Peng X, et al (2018) SnO 2 Composite Films for Enhanced. Catalysis 1-12. doi: $10.3390 /$ catal 8100453 .

[11] Seetharaman A, Nithya A, Jothivnkatachalam K (2016) Three Way Electron Transfer of C-N-S Tri Doped Two-Phase Junction of TiO2 Nanoparticles for Efficient Visible Light Photocatalytic 
Dye Degradation. doi: 10.1039/C5RA25017J.

[12] Bhatia S, Verma N (2018) Gas Sensing Performance of Dip-Coated Indium-Doped ZnO Films. Journal of Electronic Materials. doi: 10.1007/s11664-018-6533-x.

[13] Conduction BM, Conduction O, Resistivity E, et al General Introduction and Literature Survey.

[14] Sarahnaz S, Gujela OP, Afzulpurkar NV (2013) Fabrication of Light Emitting Diode with ZnO Nanorods on Polymer Coated Silicon Substrate. 295-298.

[15] Li F, Orosz L, Kamoun O, et al (2012) ZnO-Based Polariton Laser Operating at Room Temperature: From Excitonic to Photonic Condensate. Condensed Matter. doi: 10.1103/PhysRevLett.110.196406.

[16] Bhatia S, Verma N, Bedi RK (2017) Results in Physics Ethanol gas sensor based upon ZnO nanoparticles prepared by different techniques. Results in Physics 7:801-806. doi: 10.1016/j.rinp.2017.02.008.

[17] Zegadi C, Abdelkebir K, Chaumont D, et al (2014) Influence of Sn Low Doping on the Morphological, Structural and Optical Properties of ZnO Films Deposited by Sol Gel DipCoating. Advances in Materials Physics and Chemistry 04:93-104. doi: 10.4236/ampc.2014.45012.

[18] Singh G, Shrivastava SB, Jain D, et al (2010) Effect of indium doping on zinc oxide films prepared by chemical spray pyrolysis technique. 33:581-587.

[19] Senol SD (2016) Hydrothermal derived nanostructure rare earth (Er, Yb)-doped ZnO: structural, optical and electrical properties. Journal of Materials Science: Materials in Electronics 27:7767-7775. doi: 10.1007/s10854-016-4765-1.

[20] Peng $X$, Wang Z, Song $Y$, et al (2007) Structural and photoluminescent properties of ZnO films deposited by radio frequency reactive sputtering. Science in China, Series G: Physics, Mechanics and Astronomy 50:281-286. doi: 10.1007/s11433-007-0007-0.

[21] Bhatia S, Verma N (2017) Photocatalytic activity of ZnO nanoparticles with optimization of defects. Materials Research Bulletin 95:468-476. doi: 10.1016/j.materresbull.2017.08.019

[22] Bhatia S, Verma N, Bedi RK (2017) Varied Sensing characteristics of In- doped ZnO Films Prepared by Sol Gel Spin Coating Technique. 13:54-58.

[23] Bhatia S, Verma N, Bedi RK (2016) Effect of aging time on Gas sensing Properties and Photocatalytic efficiency of dye on In-Sn co-doped ZnO nanoparticles. Materials Research Bulletin. doi: 10.1016/j.materresbull.2016.12.011.

[24] Bhatia S, Verma N, Kumar R (2017) Morphologically-dependent photocatalytic and gas sensing application of Dy-doped ZnO nanoparticles. Journal of Alloys and Compounds 726:1274-1285. doi: 10.1016/j.jallcom.2017.08.055

[25] Jayachandraiah C, Kumar KS, Krishnaiah G, Rao NM (2015) Influence of Dy dopant on structural and photoluminescence of Dy-doped ZnO nanoparticles. JOURNAL OF ALLOYS AND COMPOUNDS 623:255-254. doi: 10.1016/j.jallcom.2014.10.067

[26] Bhatia S, Verma N, Bedi RK (2016) Effect of aging time on Gas sensing Properties and Photocatalytic efficiency of dye on In-Sn co-doped $\mathrm{ZnO}$ nanoparticles. Materials Research Bulletin. doi: 10.1016/j.materresbull.2016.12.011. 
[27] Marsalek R (2014) Particle size and Zeta Potential of ZnO. Procedia - Social and Behavioral Sciences 9:13-17. doi: 10.1016/j.apcbee.2014.01.003

[28] Rakhra M, Verma N, Bhatia S (2019) Structural, Morphological , Optical , Electrical and Agricultural Properties of Solvent / ZnO Nanoparticles in the Photodegradation of DR-23 Dye. doi: 10.1007/s11664-019-07760-z.

[29] Sundaram, K.B, et al (1997) Work function determination of zinc oxide films. J. Vac. Sci. Technol. A: Vac. Surf. Films 15: 428-430.

[30] Xu Z, Deng H, Xie J, et al (2006) Ultraviolet photoconductive detector based on Al doped ZnO films prepared by sol - gel method. 253:476-479. doi: 10.1016/j.apsusc.2005.12.113.

[31] Zhu Q, Lu J, Wang Y, et al (2016) Burstein-Moss Effect Behind Au Surface Plasmon Enhanced Intrinsic Emission of ZnO Microdisks. Nature Publishing Group 1-9. doi: 10.1038/srep36194.

[32] Lakhwani G, Roijmans RFH, Kronemeijer AJ, Gilot J (2010) Probing Charge Carrier Density in a Layer of Photodoped ZnO Nanoparticles by Spectroscopic Ellipsometry. 14804-14810.

[33] Photocatalysis A to Z - What We Know and What We Don 't Know in A Scientific Sense.

[34] Bhatia S, Verma N, Aggarwal M (2018) Thermal, optical and gas sensing properties of ZnO fi Ims prepared by different techniques. 10101:1-7. doi: 10.1051/epjap/2017170270.

[35] Verma N, Bhatia S (2017) Role of pH on electrical, optical and photocatalytic properties of $\mathrm{ZnO}$ based nanoparticles. Journal of Materials Science: Materials in Electronics 0:0. doi: 10.1007/s10854-017-6732-x 

Figures
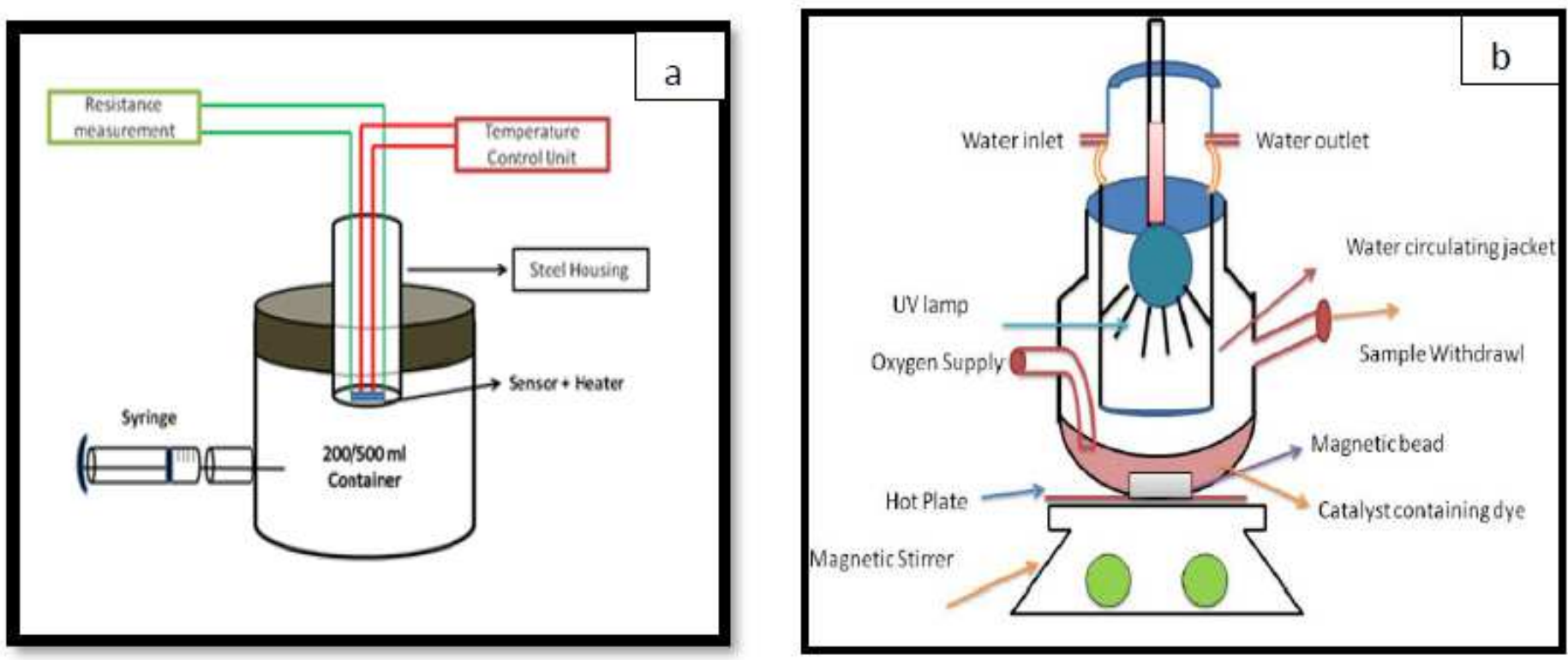

Figure 1

$(a, b)$ Static gas sensing set up, systematic scheme for photoreactor.

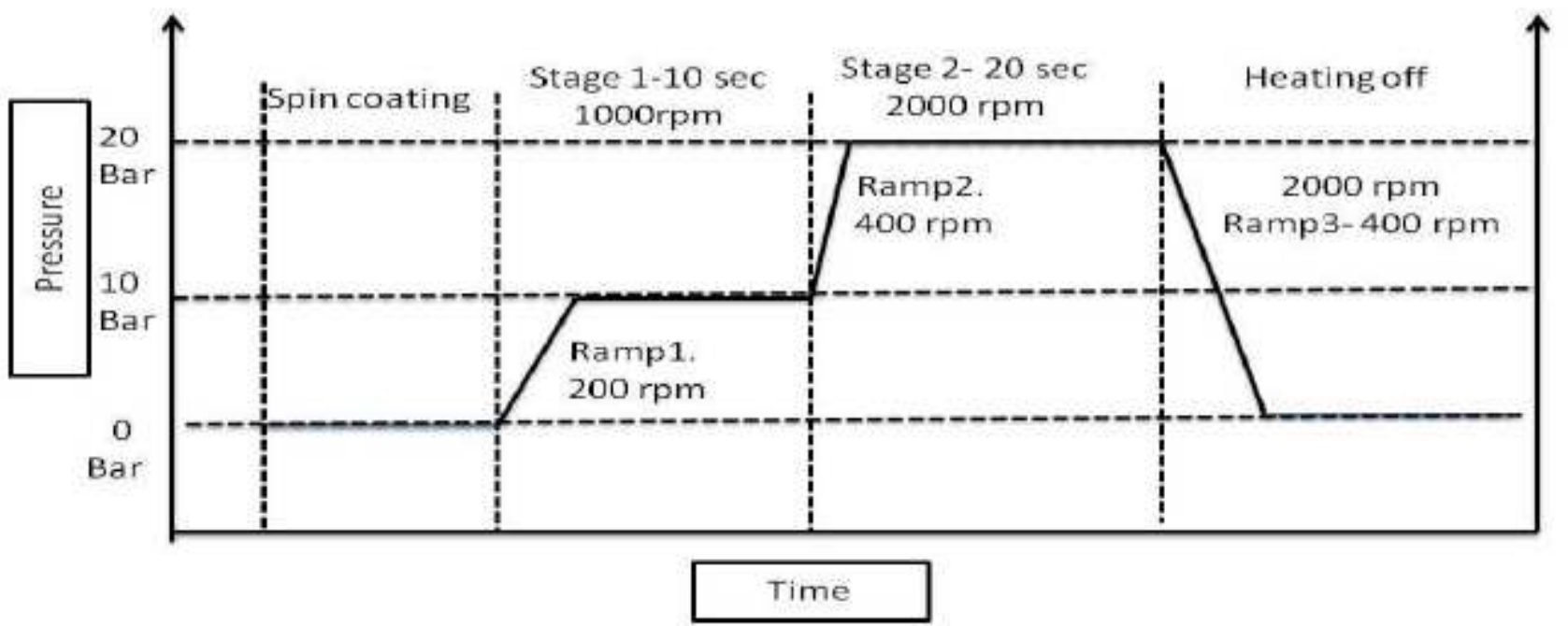

Figure 2

Programming used for the spin coating technique. 

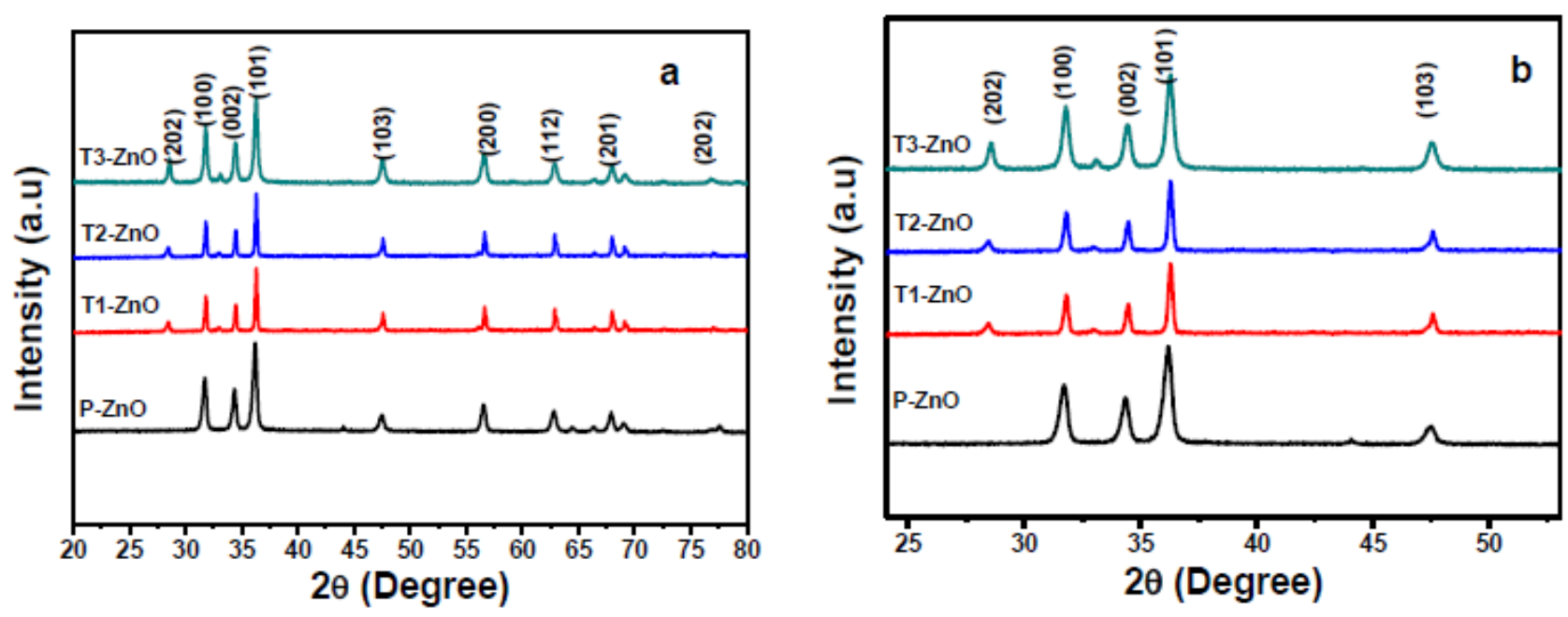

Figure 3

(a) Low and (b) magnified XRD spectra of Pure, $\mathrm{T} 1-\mathrm{ZnO}, \mathrm{T} 2-\mathrm{ZnO}$ and $\mathrm{T} 3-\mathrm{ZnO}$ respectively 

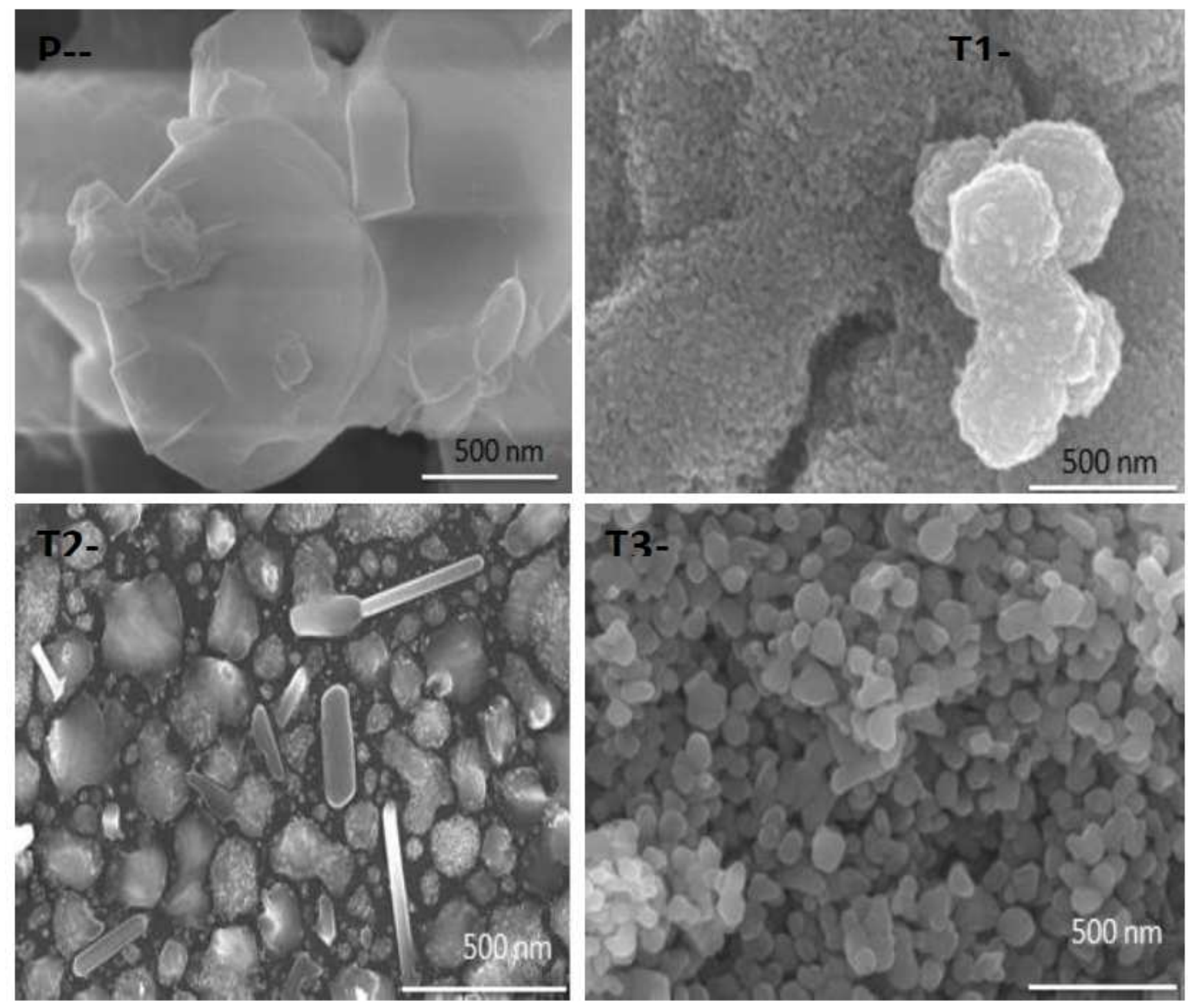

Figure 4

Typical FESEM images ( $\mathrm{P}-\mathrm{ZnO}, \mathrm{T} 1-\mathrm{znO}, \mathrm{T} 2-\mathrm{ZnO}$ and $\mathrm{T} 3-\mathrm{ZnO}$ respectively) for the pure and tridoped $\mathrm{ZnO}$ nanoparticles. 


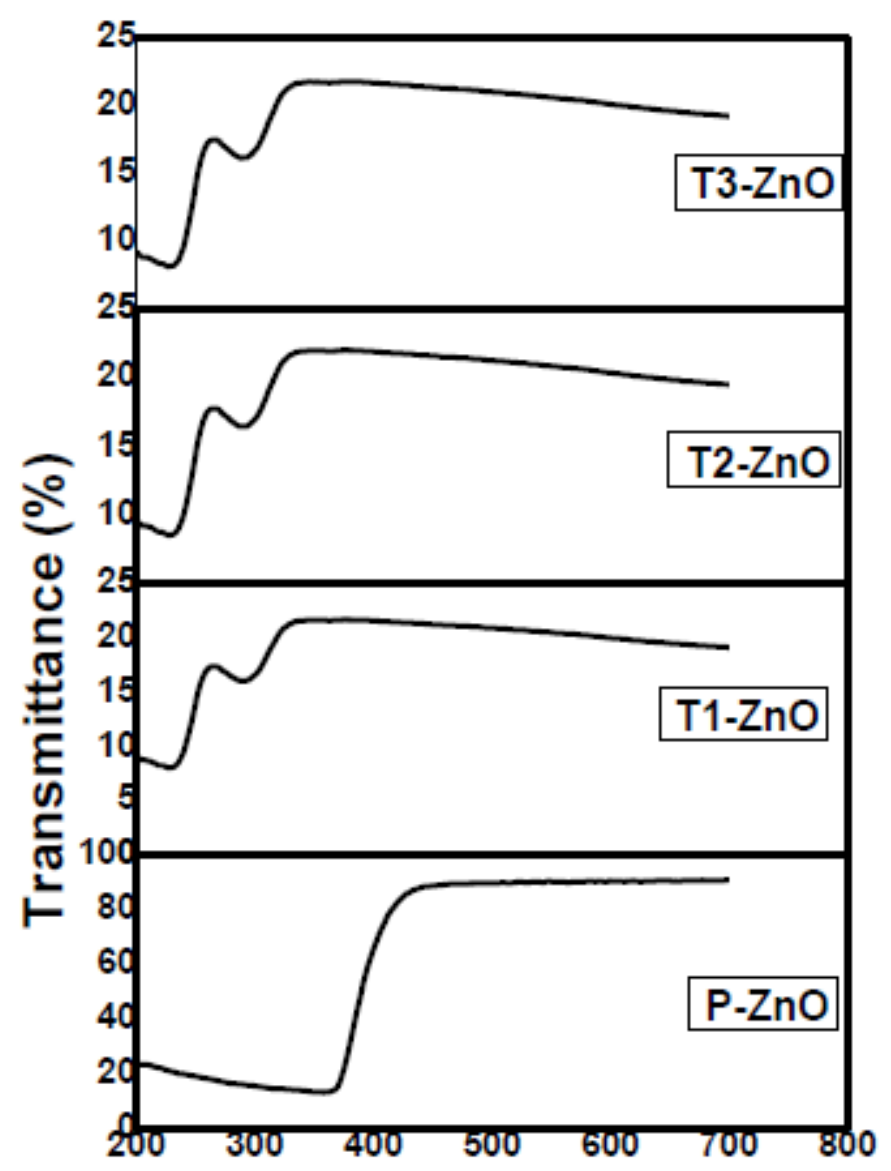

Figure 5

Typical transmittance spectra of Pure and tri-doped $\mathrm{ZnO}$ nanoparticles (P-ZnO, T1-ZnO, T2-ZnO and T3$\mathrm{ZnO}$ ) respectively.

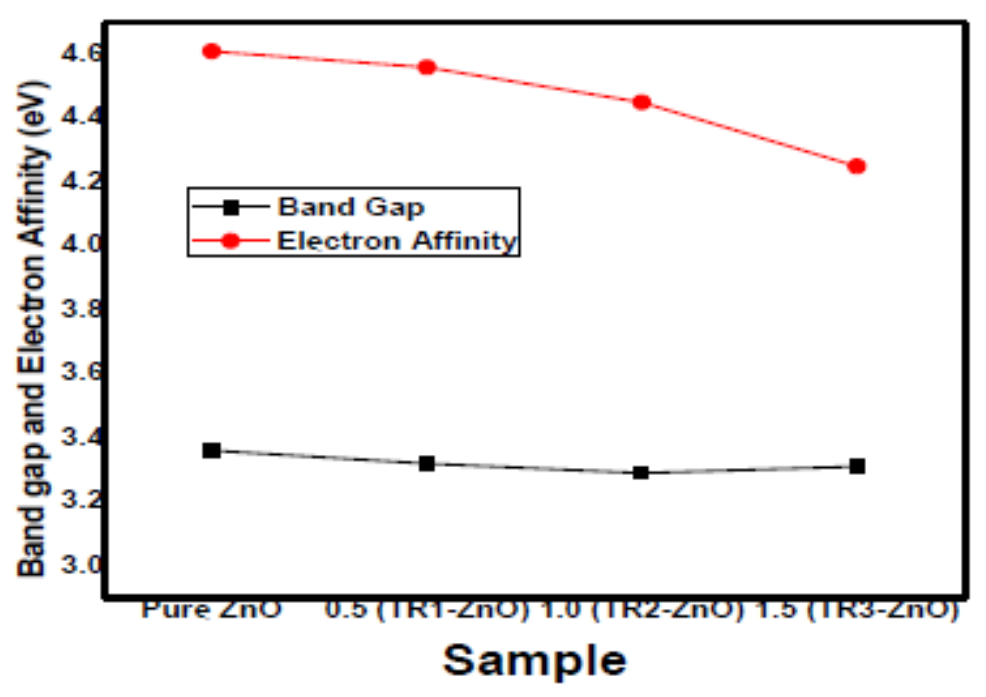

Figure 6

Variation in band gap and electron affinity due to the change in doping content. 


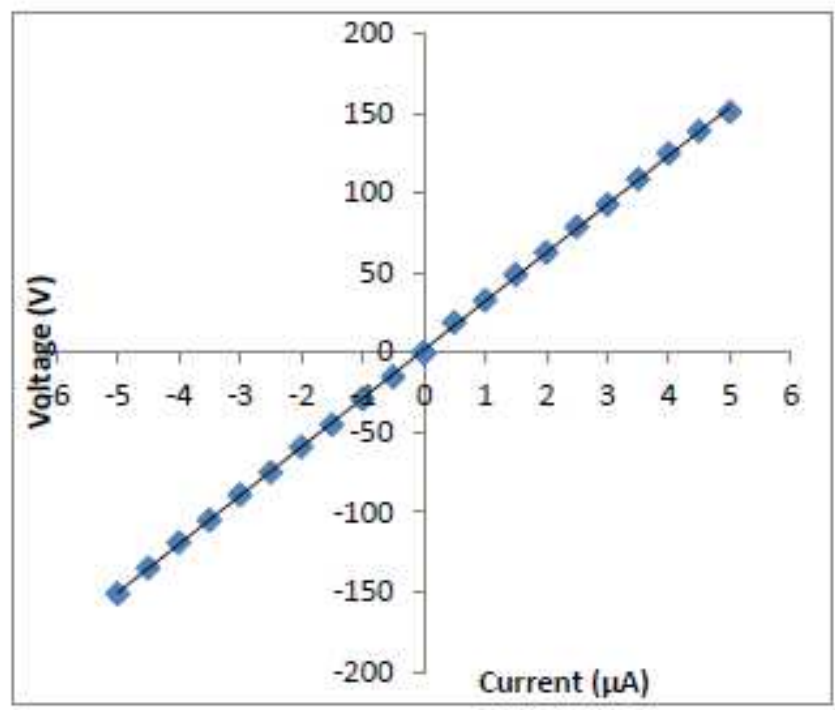

Figure 7

Linear V-I characteristics under both forward and reverse bias of $\mathrm{T} 2-\mathrm{ZnO}$ respectively.

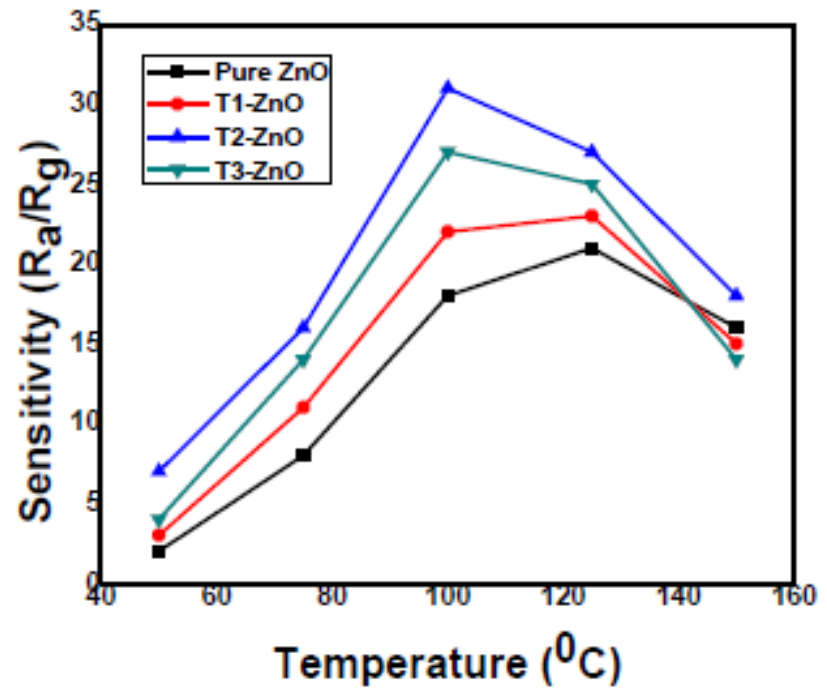

Figure 8

Sensitivity of Pure and tri-doped ZnO based sensor towards NO2 gas sensor. 

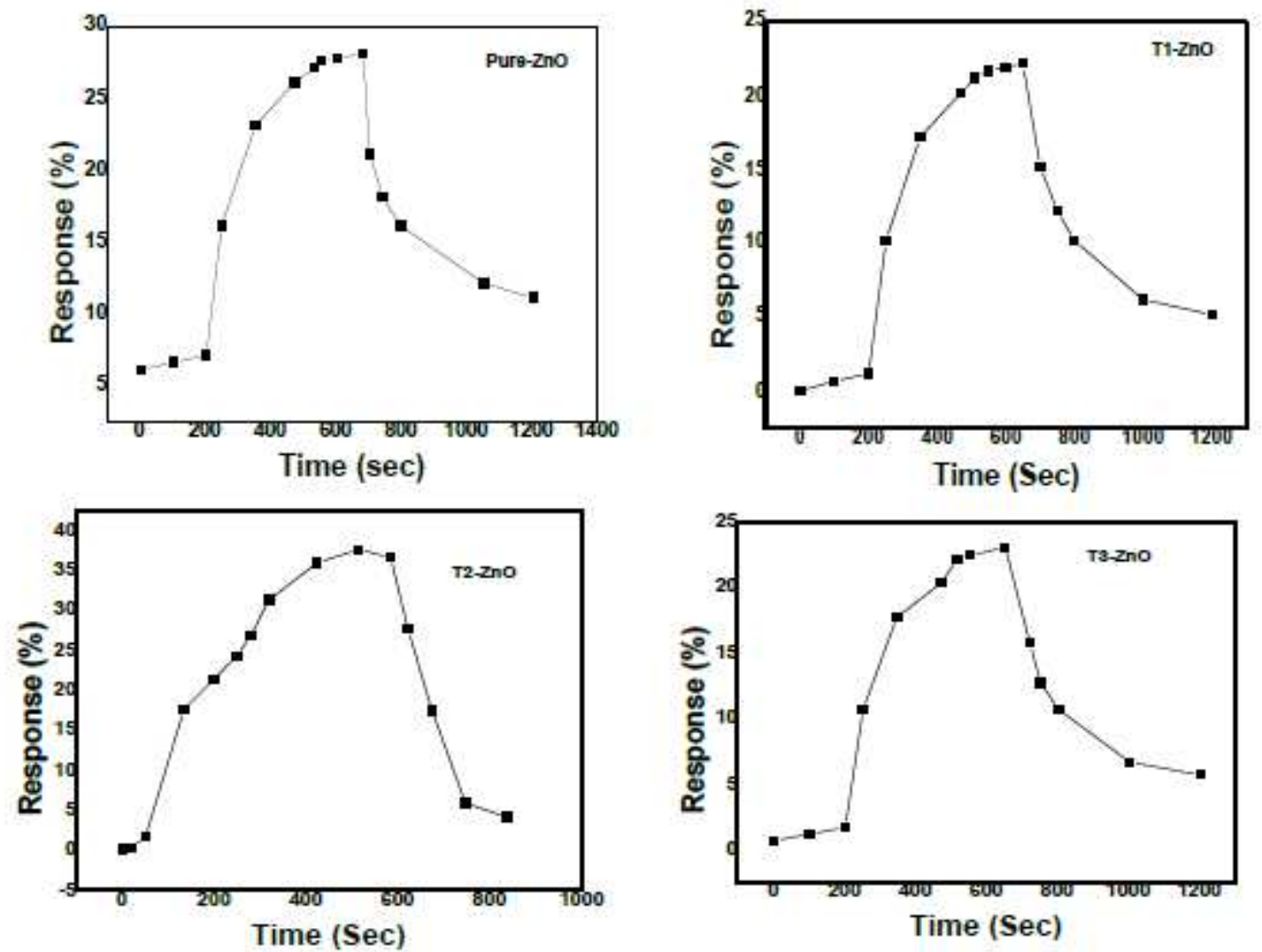

Figure 9

Gas sensing response for pure $\mathrm{ZnO}, \mathrm{T} 1-\mathrm{ZnO}, \mathrm{T} 2-\mathrm{ZnO}$ and $\mathrm{T} 3-\mathrm{ZnO}$ thin films.

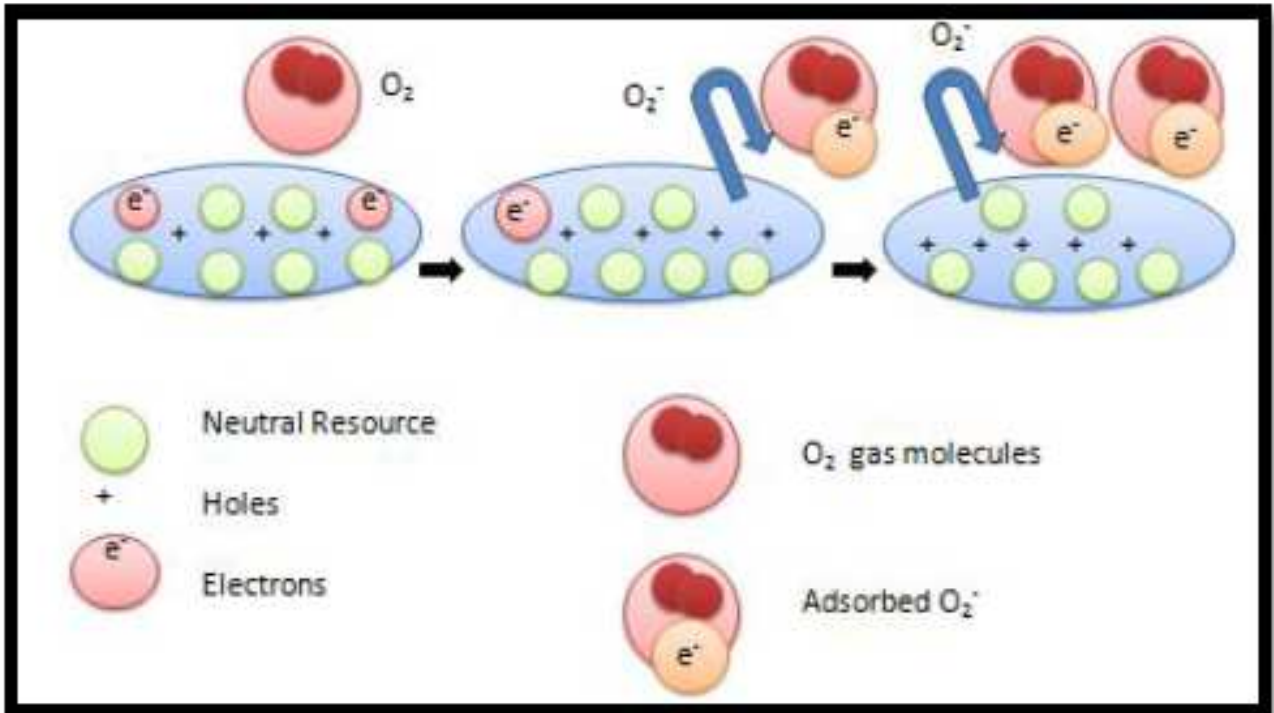

Figure 10

Schematic illustration of adsorption of 02 gas molecules. 


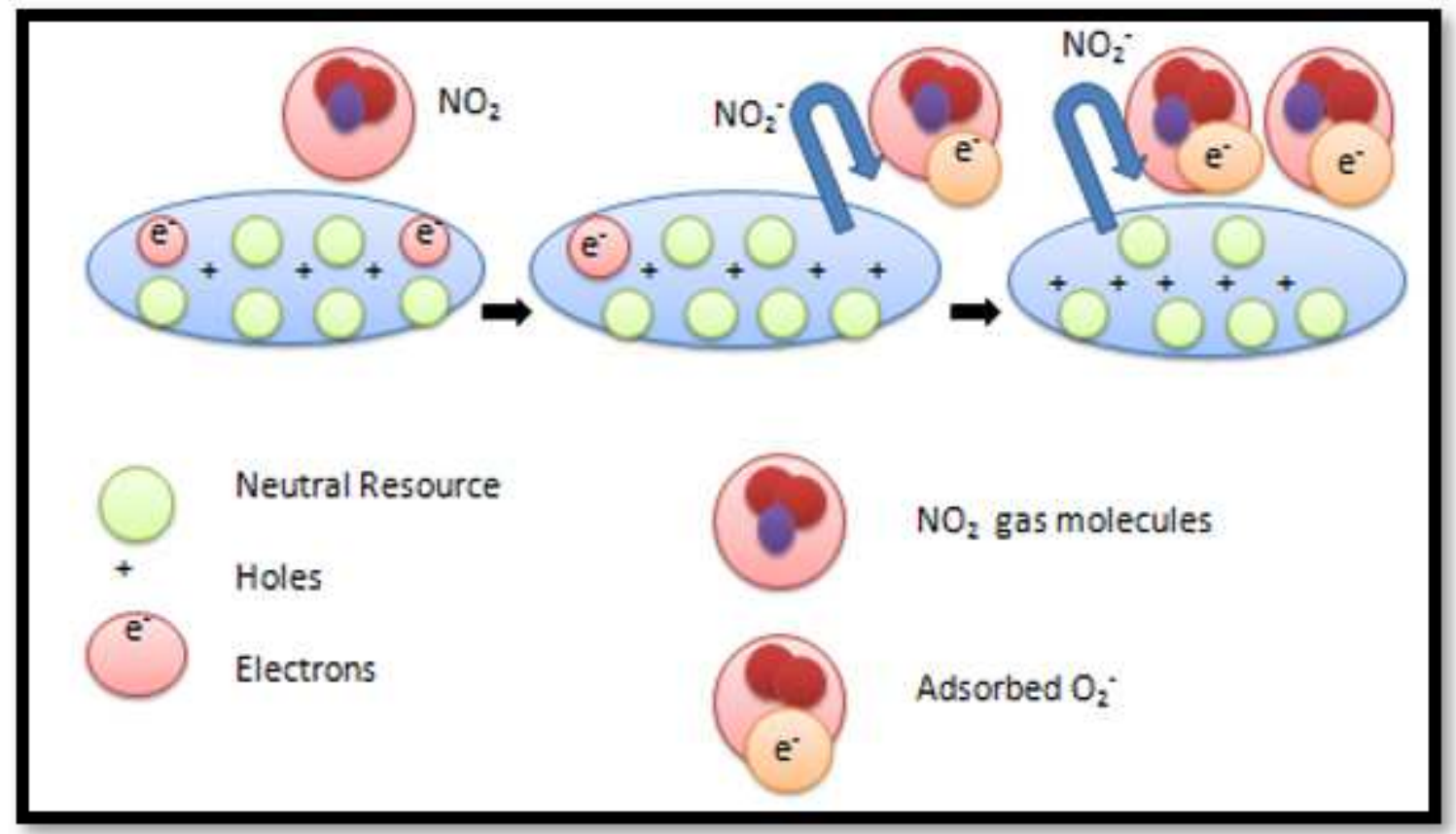

Figure 11

Schematic illustration of adsorption of NO2 gas molecules. 

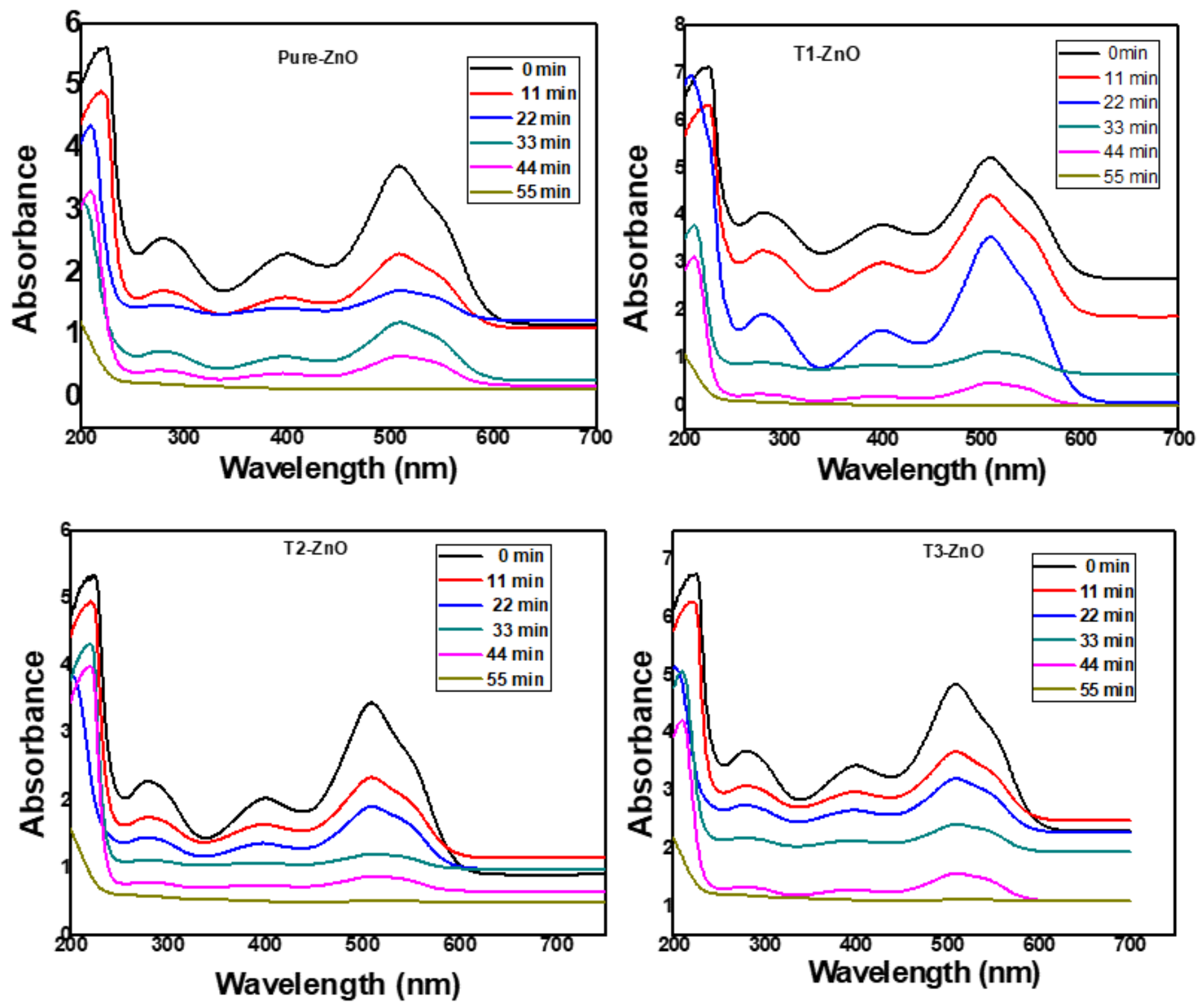

Figure 12

UV-Vis spectra plot for photodegradation of DR-31 dye for Pure-ZnO, T1-ZnO, T2-ZnO and T3-ZnO respectively. 


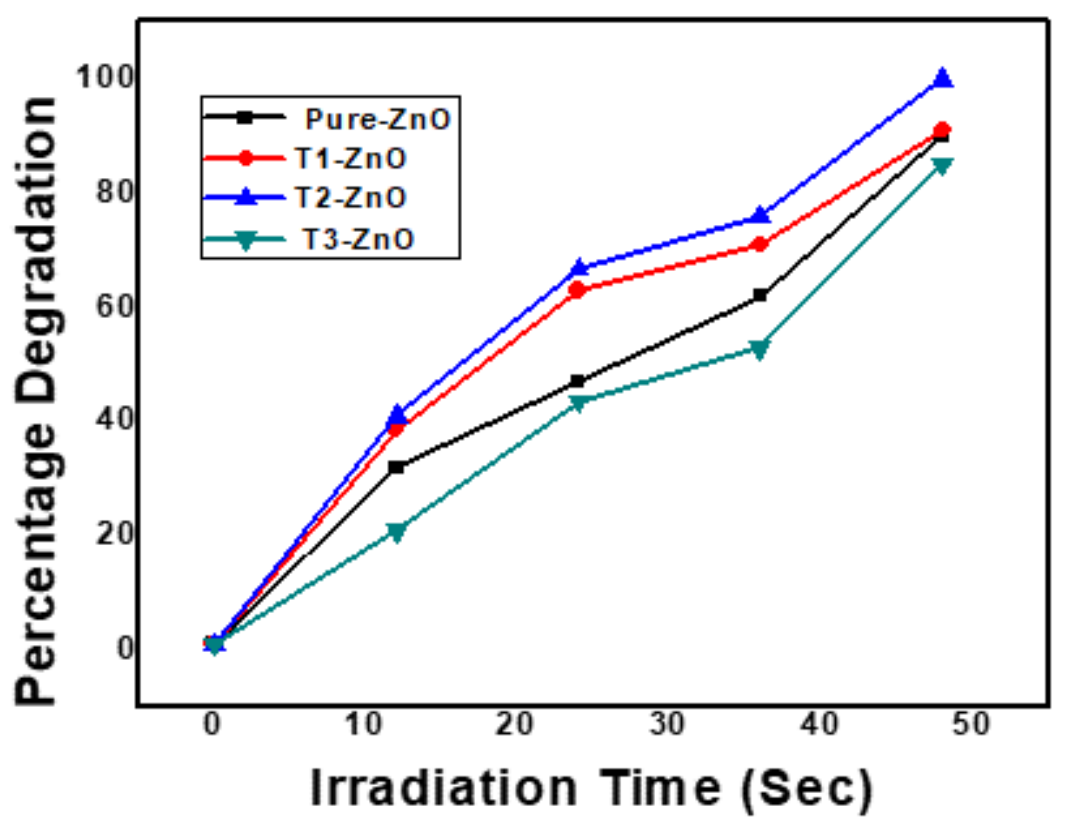

Figure 13

Percentage degradation of DR-31 dye for Pure-ZnO, T1-ZnO, T2-ZnO and T3-ZnO respectively.

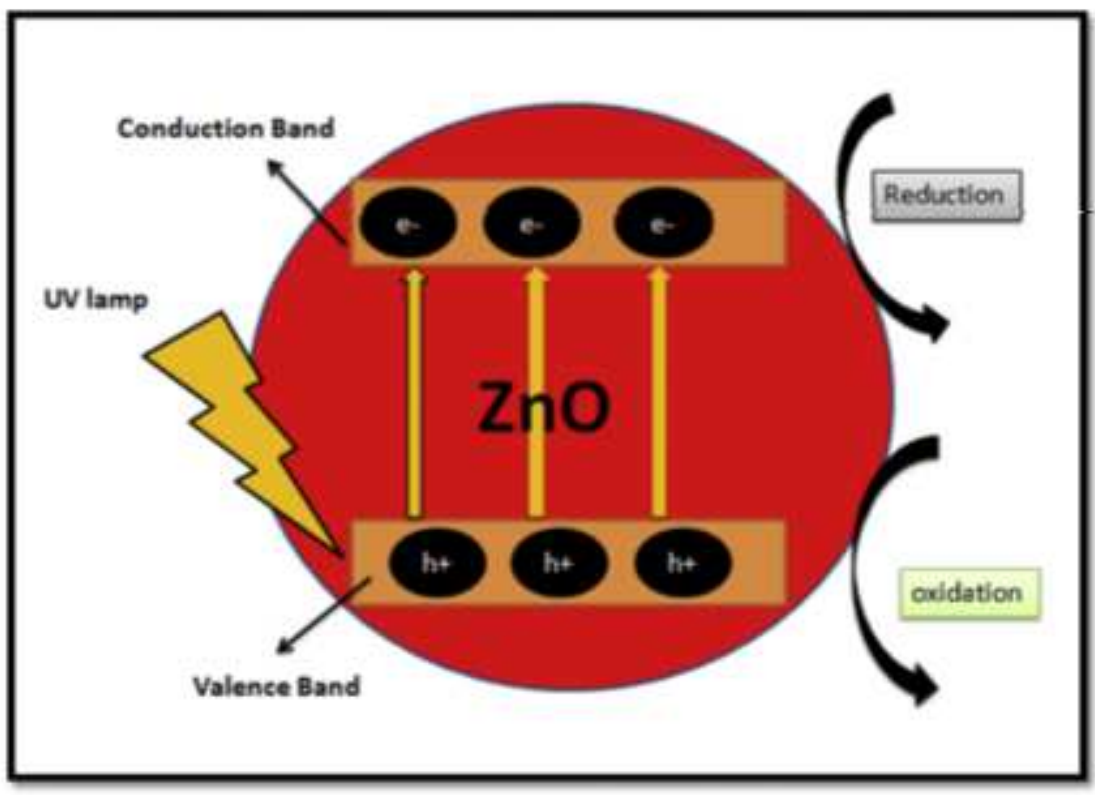

Figure 14

Mechanism for the dye degradation. 